Dr. Elnaggar, Khaled M.

Volume (2) No. (2) 2019

تأثير النشـر الدولي والسمعة الأكاديمية على ترتيب الجامعة الإسلامية بالمدينة المنورة في التصنيفات العالمية

د/ خالد محمد محمود النجار 
تأثير النثر الدولي والسمعة الأكاديمية على ترتيب الجامعة الإسلامية بالمدينة المنورة في

\section{التصنيفات العالمية}

$$
\text { د. خالد محمد محمود النجار }
$$

أستاذ مساعد المناهج وطرق التدريس، السنة التحضيرية للكليات العلمية، الجامعة الإسلامية المدينة المنورة، السعودية، drkhaledelnaggar@yahoo.com

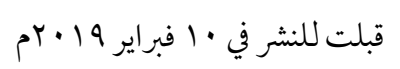

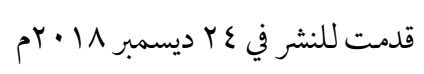

المستخلص: هدفت الدراسة إلى توضيح أهمية النشر الدولي والسمعة الأكاديمية كمعاير لتصنيف الجامعات عالميًا وفقا للمعايير المعروفة لتصنيف الجامعات في العالر، وتناولت الدراسة عرضِا لأشهر التصنيفات العالمية للجامعات والتي تسعى الجامعة الإسلامية الدخول المي هذه التصنيفات، وهئ على الترتيب: تصنيف شنغهاي (ARWV))، تصنيف ويب ماتركس (Webometrics)، و تصنيف ستار كيواس (QS))، تصنيف التايمز (Times) حيث التعريف بالتصنيف، وتوضيح ترتيب الجامعة الإسلامية بالمدينة المنورة وكانت أهم النتائج ما يلي:- تواجد الجامعة الإسلامية بالمدينة المنورة التصنيف العالمي (Webometrics) للمواقع الجامعية والتعليمية، حيث دخلت الجامعة الإسلامية التصنيف "ويب ماتريكس" حيث التصنيف العالمي (0119) وعلن مستوي التصنيف القاري

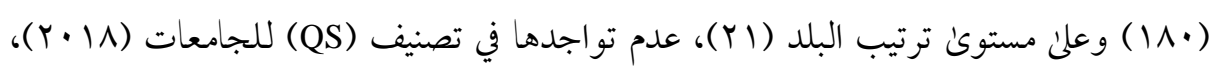
واختفاءها وفق تصنيف التايمز أسوة ببعض الجامعات المحلية والعربية والدولية، تواجد الجامعة

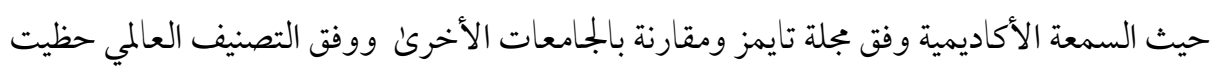
علن المرتبة (5119)، والتصنيف القاري حظيت (180)، ووفق ترتيب البلد حظيت (21)، ووفق الحضور حظيت (6606) ووفق التأثير حظيت (4482)، ووفق الانفتاح حظيت (3958) ووفق

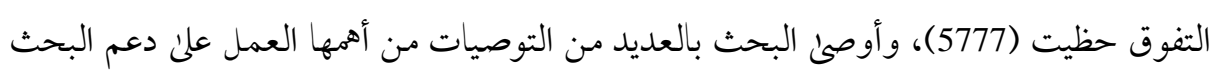
العلمي بالجامعة وكل المراكز والوحدات التابعة للجامعة بتقديم كافة الخدمات لأعضاء هيئة 
Dr. Elnaggar, Khaled M.

Volume (2) No. (2) 2019

التدريس ومساعدتهم علن إجراء البحوث العلمية، إقامة ورش العمل الفعلية والتطبيقية للتعرف التصنيفات العالمية للنهوض بالجمعة وطرق تفعيلها. الكلمات الدلالية: النشر الدولي، السمعة الأكاديمية، التصنيفات العالمية للجامعات. 


\title{
The Impact of International Publication and Academic Reputation on the Ranking Islamic University of Madinah in International Classifications
}

\author{
Dr. Khaled M. Elnaggar \\ Assistant professor of Curriculum and instruction, Preparatory Year for Scientific, \\ Islamic University of Madinah College, Saudi Arabia. \\ drkhaledelnaggar@yahoo.com
}

Received 24 December 2018

Accepted in 10 Feb 2019

\begin{abstract}
The study aimed at clarifying the importance of international publication and academic reputation as a standard for the classification of universities internationally according to the recognized standards of the classification of universities in the world. The study dealt with the world rankings of the universities which the Islamic University is seeking to enter these categories, respectively: Shanghai Classification (ARWV) (Webometrics), classification of Star Quas (QS), classification of the Times (Times) where the definition of classification, and clarify the order of the Islamic University in Madinah and the most important results are: The presence of the Islamic University in Madinah World Ranking (Webometrics) Alimiya, where the Islamic University entered the classification of "Web Matrix" where the global classification (5119) and the level of continental classification (180) and the ranking of the country (21 (1808), and its disappearance according to the classification of the Times, as well as some local, Arab and international universities, the university's academic reputation according to the Times magazine and compared to other universities according to the rankings ranked (5119) In accordance with the ranking of the country, (21) and (6606). According to the effect, there were (4482). In accordance with the openness, there were (3958) and according to excellence, (5777). The research recommended several recommendations, the most important of which is to support scientific research in the university and all centers And university units to provide all services to faculty members and help them to achieve Scientific
\end{abstract}


researches, the establishment of actual and applied workshops to identify international classifications for the advancement of the university and ways of activating them.

Keywords: International publication - Academic reputation - International rankings of universities 


\section{Summary}

\section{Introduction}

The Islamic University of Madinah is seeking to find an advanced ranking in the international classifications of universities, which is currently one of the reliable evidence in giving indications of the university's ranking among the international universities. Therefore, the pursuit of achieving a prestigious position within these classifications is a primary goal for each university, Only all universities seek it.

Excellence in the university education is always in keeping with the changes in knowledge and benefit from and develop them, in addition to that the university education should be based on the development of culture and creativity among students and faculty members (Qutb, 2008, 12).

In recent times, international publishing has become of major importance as it has become a cornerstone and a major factor in the classification of universities worldwide. The funding of research projects in most parts of the world also depends on the number of international research published for researchers and research groups. To encourage its researchers and scientists to publish international awards of financial based on the classification of scientific journals and impact factor factors each magazine and the number of reference citations to the total number of published research according to the calculations announced by Google Scholar, resulting in a clear increase in The rate of international dissemination of university researchers and the improvement of the scientific research index. (Ibase et al., 2015,144)

\section{Research problem}

The topic of international classifications is one of the basic elements that helps universities to be present in the scientific and academic fields where scientific production and academic reputation. This also increases the Islamic University in Madinah spread and strength among the local, Arab and international universities for its local and international status as well. Production and assembly after encouraging faculty members to publish at the international level and improve the academic reputation of the university, where the university brought together forensic science 
and other sciences (science, computer, engineering, preparatory year). Faculty of Science).

The current research problem is determined by the low number of studies and researches of the Islamic University and its entry into international classifications, as it has students from the world level and also faculty members. Therefore, these data should be placed through the electronic portal and the University's entry into the International Classification Center.

\section{Objectives :}

Current research targeted the following:

- Revealing the extent of the impact of international classifications of universities that have emerged the Islamic University in Madinah.

- To identify the Islamic University site in Madinah Al Munawwarah in the world, Arab and local categories.

- Disclosure of the academic reputation of the Islamic University in Madinah in the light of international classifications.

\section{Measures}

Research Methodology: The researcher used the descriptive method to monitor the information he sees about some universities and the extent of their progress, and between the Islamic University and the way of development to reach all international classifications and the university's progress.

Sample research: Islamic University where publishing - academic reputation

Research procedures: To answer the research questions and verify the veracity of his duties, follow the following procedures:

- Access to previous research and research related to the subject of research.

- Formation of a theoretical framework for research

- Access to sites that are concerned with the international classifications of universities: 
- First: Shanghai Classification: Academic Ranking of world Universities by.

- Second: Web Ranking Matrix: Webometrics: World Universities' Ranking on the web by Cybermetrics Lab.

- Third: Star Rating QS Stars.

- Fourth: Times classification for the ranking of universities of higher education.

- $\quad$ Analysis of the results

- Interpretation of results

- Recommendations

- References

\section{Results}

- The Islamic University in Madinah, the world ranking of the Webometrics for the university and educational sites, where the Islamic University entered the classification "Web Matrix" where the classification of the world (5119) and the level of continental classification (180)

- The absence of the Islamic University in Medina in the classification of (QS) for universities (2018)

- The disappearance of the Islamic University according to the classification of the Times, similar to some local universities, Arab and international.

- The presence of the Islamic University in Madinah, where the academic reputation according to the Times magazine and compared to other universities and ranked in the ranking of the world ranked (5119), the continental classification has won 180, and according to the ranking of the country received 21, and received the presence of (6606) 4482). According to openness, there were (3958). 


\section{مقدمة}

تسعى الجامعة الإسلامية بالمدينة المنورة إيجاد ترتيب متقدم في التصنيفات العالمية للجامعات؛

والتي تعد حاليًا أحد الأدلة التي يُعتمد عليها في إعطاء مؤشرات عن ترتيب الجامعة بين الجامعات الجمات العالمية، لذلك أصبح السعي وراء تحقيق مركز مرموق ضمن هذه التصنيفات هدف أساسي لكل جامعة وليس الجامعة الإسلامية بالمدينة المنورة فقط بل تسعى كل الجامعات لذلك. فالتميز في التعليم الجامعي يقوم دائًا على مواكبة التغيرات المعرفية والاستفادة منها وتطويرها، بالإضافة إلى أنه يجب أن يكون التعليم الجامعي قائمًا على تنمية الثقافة والإبداع لدئ

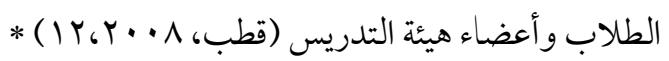
وتعد تجربة تصنيف الجامعات تجربة حديثة ومعاصرة وعدد الدول التي خاضت هذه التجربة قليل، إذ أن هناك عددًا من المحاولات بين الجامعات لوضع تصنيفات علن المستوي المحلي، بمعنئ قيام بعض الدول مثل الولايات المتحدة الأمريكية، بريطانيا، ألمانيا، بوضع تصنيفات لجامعتها فقط، دون أن يتعدئ هذا التقويم الحدود الإقليمية، ليضم الجامعات الأخرىن، وتجدر الإشارة إلى أن الدول التي خاضت عمار هذه المحالات في التقويم، تلك الدول التي تحرص على تطوير جامعتها ومؤسساتها البحثية والأكاديمية، وذلك على الرغم من أنها تتمتع بأساليب وأنظمة تعليمية وبحثية على مستون

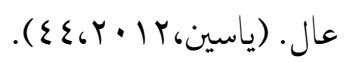
فالتصنيفات العالمية للجامعات من أبرز المؤشرات التي يمكن الاستدلال بها على جودة الجامعة ومدى تطورها، إذ تسعئ معظم الجامعات التي تهدف إلى تحسين صورتها وسمعتها إلى الأخذ بالمعايير التي تضعها أشهر التصنيفات، وعليه فهذه التصنيفات تعكس جانبًا كبيرًا من جودة التعليم

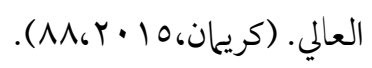

وفي الفترة الأخيرة صار لاكتساب النشر الدولي له أهمية كبرىن حيث أصبح ركيزة أساسية وعامل من أهم أسس تصنيف الجمامعات عالميًا، كما أصبح تمويل المشروعات البحثية في معظم أنحاء 
العالر يعتمد أيضًا علن عدد الأبحاث الدولية المنشورة للباحثين والمجموعات البحثية، ولذلك اتجهت العديد من الجامعات في الآونة الأخيرة إلى تحفيز باحثيها وعلمائها للنشر الدولي بمنح جوائز مالية

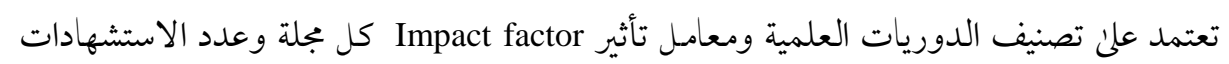

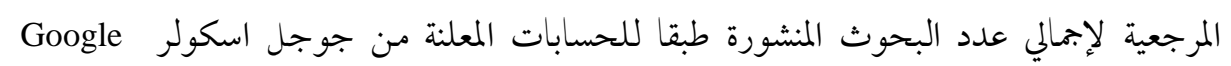
Scholar

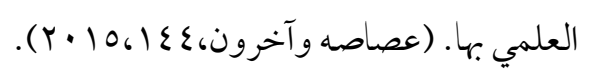

وأصبح التصنيف عملية ذات أهمية عالية للجامعات، وللعديد من المستفيدين من نتائجه، وتتأثر إدارة الجامعة المنشغلة بإعداد الأهداف المؤسسية والعملية بنتائج التصنيف؛ حيث يؤثر علن عملية التدويل الأكاديمية التي تشجع على التنقل بين أعضاء هيئة التدريس والطلاب، وتؤكد بالتالي على الحاجة إلى المقارنة العالمية لنظم التعليم العالي، والبرامج الدراسية، والدرجات العلمية، وقد ثبت لتبل أن التصنيف يعزز المنافسة الدولية بين الجامعات، من أجل إيياد بيئة تعليمية جاذبة متعددة الثقافات، والاتجاه نحو التعاون بين الجامعات، والأهم من ذلك فرصة لتحسين ومعالجة مواطن الضعف لدئ الجحامعات .(Ismail, 3, 2008).

ولقد تحول العالم نحو التركيز علن مقارنة الجامعات والتخصصات ليس فقط من الطلاب و أهاليهم بل حتى من الجامعات نفسها والحكومات ...الخ. إذ أن كثيرًا من الطلاب وأولياء الأمور

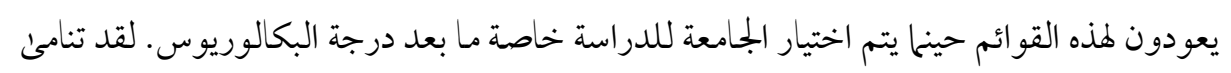

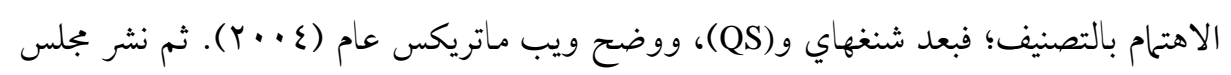

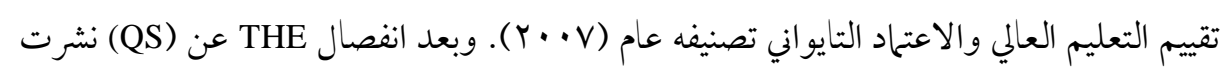

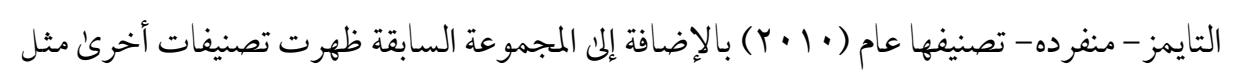

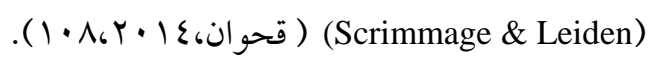


ومن المتوقع ظهور الجامعة الإسلامية في بعض التصنيفات وان لم تظهر في البعض وذلك يتضح من خلال ما تتوصل اليه الدراسة حيث الأسباب والأليات في تحسين عملية الظهور في التصنيفات العالمية.

\section{التصنيف الأكاديمي للجامعات}

يقصد بالتصنيف الترتيب (Ranking) هو الدرجة الكلية التي تحصل عليها المؤسسة من خلال جمع المؤشرات المختلفة وتخضع لعمليات حسابية وتطبيق الأوزان ومن ثم تستخرج النتيجة الكلية للمؤسسة المعنية، ويتم تحديد ترتيب المؤسسة من بين عدد المؤسسات المتقدمة للحصول علئ

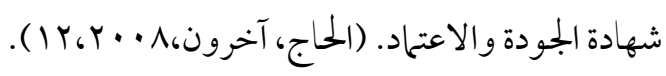

ويشار اليه أيضا علن أنه أسلوب لتنظيم مجموعة محددة من الأشياء التي قومت من خلال معايير نختلفة مما يوفر وضعًا أكثر شمولية للأشياء و يجعل تنظيمها من الأفضل إلى الأسو أ مهمة أكثر

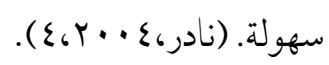

\section{مفهوم التصنيف العالمي للجامعات}

نظام ترتيب الجامعات من حيث المستون (الأكاديمي-والعلمي - الأدبي) فهذا الترتيب يعتمد علن بجموعة من الإحصاءات أو استبانات توزع علن الدارسين والأساتذة وغيرهم من الخبراء

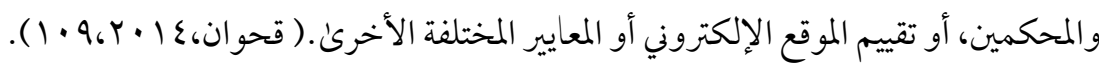
ويشار اليه في هذا البحث " مجموعة من المعايير المعدة من بعض المنظطات العالمية تقوم علن أسس معينة ويتم تحكيمها من خلال المختصين حيث توفر المؤشرات والبنود وفق التصنيف المراد الحصول عليه.

التصنيف الأكاديمي لجامعات العالم ويشار اليه أيضًا بأنه ترتيب صنف من قبل معهد التعليم العالي التابع لجامعة شانغهاي جياوتونغ ويضم كبرئ مؤسسات التعليم العالي مصنفة وفقًا لصيغة محددة تعتمد علن عدة معايير.

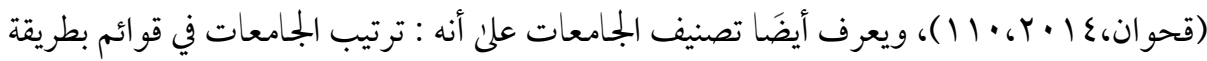


مقارنة تبعًا لمجموعة من المؤشرات العامة ترتيبًا تنازليا ويتم عرضها في صورة جداول من الأفضل إلى الى الأسوأ طبقًا لما تحرزه من نقاط وفق مجموعة من المعايير. (Usher, A\& savino,2007). ويمثل التصنيف للجامعات أهمية بالغة كونه يعطي الجامعة مؤشرًا عن موقعها بين الجامعات العالمية وفقاً للمعايير التي بنيت عليها هذه التصنيفات ولقد سعت الجامعات العالمية سعيًا حثيثاً لتأمين المتطلبات اللازمة للتوافق مع هذه المعايير التصنيفية للجامعات العالمية لتحسين بيئتها التعليمية، ولتمكين طلابها من الإجادة في مجالات العمل المختلفة. (الجامعة الأمريكية، ب ا • Y، O).

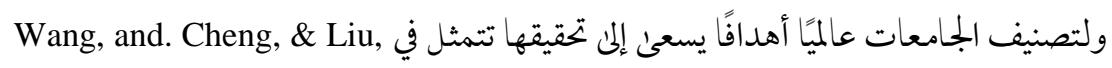

$$
\begin{aligned}
& \text { - تزويد المجتمع بمركز المؤسسة الأكاديمية مقارنة بالآخرين. } \\
& \text { - - تشجيع الجامعات للتطوير المستمر. } \\
& \text { - تحسين التنافس الإيجابي بين الجامعات. } \\
& \text { - - إدراك البعد التمويلي وأهميته في موازنة الجامعات. } \\
& \text { - قياس المخرجات اعتمادا علئ المدخلات. }
\end{aligned}
$$

- استخدام مقاييس الجودة وأخذ رأي النظر اءوخبراء الجودة. - توضيح كل الطرق المستخدمة في عملية الترتيب للمستفيدين؛ وكيفية عرض النتائج المستخلصة.

- - استقطاب الطلبة و أعضاء هيئة التدريس للالتحاق بالجامعات.

$$
\text { - - مساعدة الحكومات وسلطات الاعتماد بأمر التقييم. }
$$

- التعرف بطبيعة المؤسسة التعليمية والأخذ في الاعتبار رسالتها وأهدافها. 


\section{أهمية التصنيفات العالمية}

وتتلخص أهمية التصنيفات العالمية للجامعات فيما يلي:

- تعد مؤشر رصد، وبيان توثيق لما يحدث من تغيرات بمرور الزمن في مناسبات مؤسسات

التعليم الجامعي، وذلك علن المستويين المحلي والعالمي. (Ismail,2008, 3).

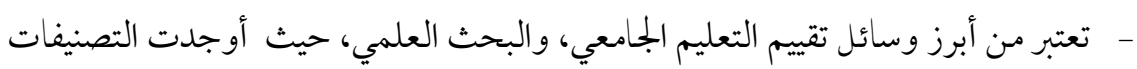

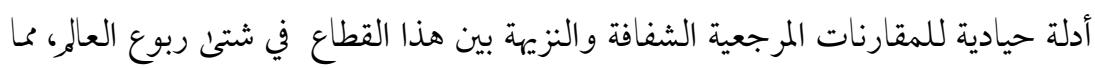

يدفع إلى التسليم بأن تدرج الجامعات في قوائم التصنيفات تعكس قيمة الجامعة النسبية

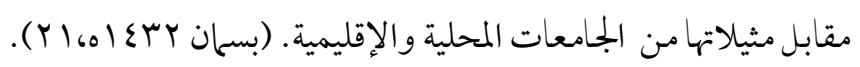

- - وضوح ما يجدث من تغيرات بمرور الزمن في الوضع الإقليمي والدولي لكل جامعة وتستخدم

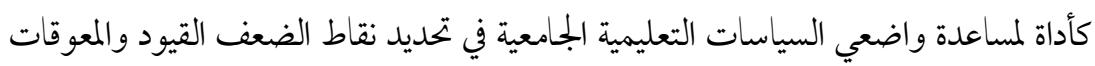

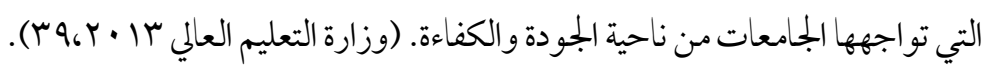

- العمل على دعم وتفعيل عملية الترويج والتسويق لمخرجات البحث العلمي لمختلف

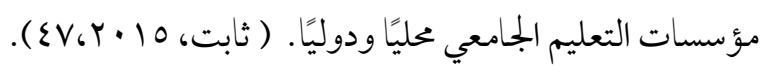

- نشر الثقافة العلمية بين كافة العاملين والمنتسبين لمؤسسات التعليم الجامعي علن اختلاف مستوياتهم (أعضاء هيئة تدريس- طلاب - رؤساء أقسام- عمداء كليات- إداريين)

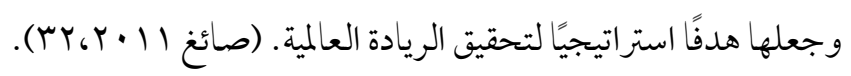

- تؤثر نتائجها على السمعة الأكاديمية للجامعة، وعلى مدى قدرتها علن استقطاب الطلاب،

حيث توفر هم المعلومات التي يجتاجون اليها لاختبار الجامعة وتلبي احتياجاتهم. (باخت

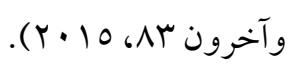

http://dx.doi.org/10.29009/ijres.2.2.5 
مبادئ يجب مر اعاتها في التصنيفات العالمية للجامعات وضعت منظمة اليونسكو مبادئ برلين حول ترتيب معاهد التعليم العالي، وقسمت هذه

$$
\text { المبادئ إلى أربعة محاور أساسية وهي: - }
$$

- التصميم والوزن النسبي للمؤشرات المستخدمة في الترتيب بين الجامعات.

$$
\text { - - جمع ومعالجة البيانات بدقة. }
$$

ينبغي التأكيد علن وضوح الأهداف المتعلقة بالترتيب ومصادر البيانات التي يعتمد عليها، وتثبيت الأوزان النسبية للمعايير المستخدمة في الترتيب ومراعاة المعايير الأخلاقية، والسياقات

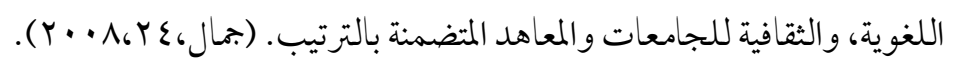

$$
\text { أنواع التصنيفات العالمية للجامعات }
$$

تصنيفات الجامعات متعددة ومنها التصنيفات الدولية، ومن أشهر المؤسسات التي تقوم بهذا النوع من التصنيف الدولي معهد التعليم العالي بالصين، والنوع الثاني هو التصنيفات المحلية التي تقوم بترتيب الجامعات علن المستوي المحلي حيث تم ترتيب الجامعات داخل الدولة فقط دون أن يتطرق إلى

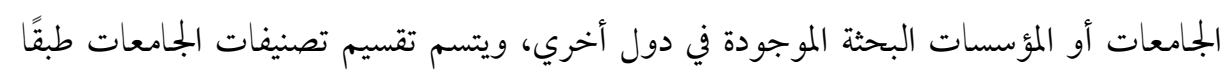

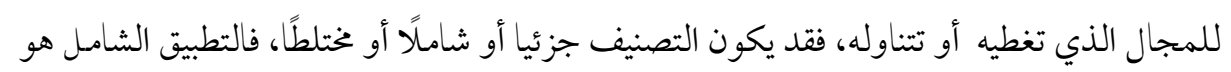
أكثر أنواع التصنيفات شيوعًا بين الجامعات، وفيه يتم إعطاء كل مؤشر من مؤشرات التقويم بدرجة

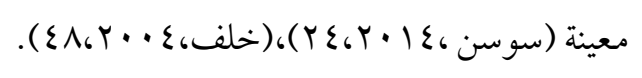$$
\text { كيف يتم التصنيف الأكاديمي للجامعات }
$$

يعد الترتيب العالمي للجامعات يعتبر أداة قيمة لبيان ما يحدث من تغيرات بمرور الزمن في

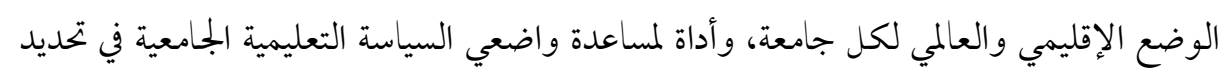
نقاط الضعف والقيود والمعوقات التي تواجهها الجامعات من ناحية الكفاءة والجودة، وتحديد أفضل 
الطرق والممارسات لتطوير المستوي التنافسي للجامعة، من خلال الاقتداء بأفضل جامعات العالم

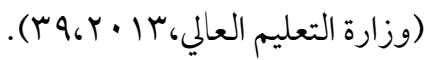

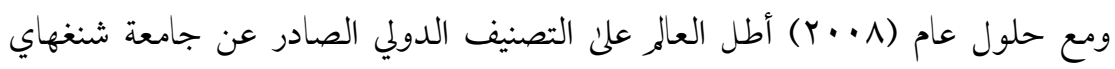
والذي وضع جامعة القاهرة وهي من أعرق الجامعات العربية في نهاية التصنيف، ونتيجة لهذا الحدث

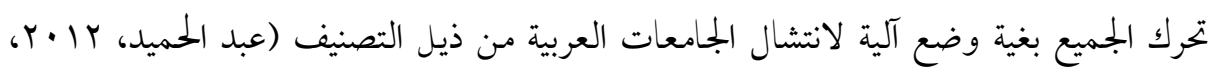
$(Y \cdot Y$

وظهرت العديد من الشواهد والأدلة التي تؤكد علن أن تصنيف الجامعات يؤثر ايجابيًا علن الجامعات التي حققت مكانة متقدمة في هذه التصنيفات وظهر هذا الأثر تحديدًا علن اتخاذ القرار الأكاديمي كتعديل المناهج الدراسية، ونشر إنتاجها البحثي باللغة الإنجليزية، وإعادة التوازن بين البحث والتدريس، وما يتبعه من إجراءات وانعكاس ذلك علن بنية النظام الجامعي وعلئ المؤسسة وخاصة فيما يتعلق بتوزيع المخصصات المالية. (Hazelkorn,2009.5).

\section{أقسام التصنيفات العالمية للجامعات}

وتنقسم التصنيفات إلى نوعين، النوع الأول: يركز علن الخبرة الجامعية من حيث التدريس

ويشمل خمسة تصنيفات هي: أخبار الولايات المتحد(US News) ، والتقرير العالمي World) (The من كندا، والجارديا (Macleans) من الولايات المتحدة الأمريكية، وماكلينز (Guardian) (التايمز (The times) من المملكة المتحدة، حيث تستهدف جميعها طلاب الجامعة، وتعتمد علئ عدة مقاييس تتصل بالخبرة المباشرة وغير المباشرة في التعليم، معتمدة بشكل عام علئ نسب الطلاب إلى وأعضاء هيئة التدريس، معدل الإنفاق علن الطلاب، ومستوى رضاهم، أما النوع الثاني: فيركز علن الأبحاث فوق الجامعية وتحته تصنيفان هما: تصنيف جامعة (شنغهاي جياوتونغ) (Shanghai Jiao Tong University Academic Ranking of الأكاديمي للجامعات العالمية World Universities- SJTU ARWU) ؛ Higher Education- Quacquarelli Symonds Ltd. - World University Rankings

\section{http://dx.doi.org/10.29009/ijres.2.2.5}


ركزا بشكل كبير علي الأبحاث واستهدفا جمهور مصادر التمويل والباحثين الأكاديميين المتميزين، وشملت المؤشرات الأبحاث المنشورة، والمستشهد بها، وعدد من أبحاث الطلاب، والجو ائز المرموقة

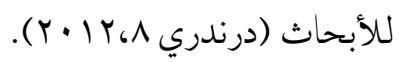
وسوف يتناول البحث الحلاي التصنيفات (أو لاً : تصنيف شنغهاي: Academic Ranking of Webometrics: World : ثانيًا: تصنيف ويب ماتركس: world Universities by SJTU QS ) : Universities' Ranking on the web by Cybermetrics Lab (Stars واعتمد البحث الحالي علن العديد من الدراسات العربية والأجنبية التي اهتمت بالتصنيفات الدولية للجامعات ومن أهم هذه الدراسات ما يلي: - وضحت دراسة ليفين وآخرون (Levin,et,al.2006) حيث استهدف البحث توضيح معنئ أن تكون جامعة مصنفة عالميًا، وتحديد معايير الوصول إلى التصنيف العالمي، ومناقشة النتائج الإحصائية المقدمة من بعض المؤسسات المصنفة استنادًا إلى سمعتها من خلال واحدة من كبري مؤسسات حصر الجامعات في العالم، إضافة إلى تصنيفات فردية لمدارس وأقسام أكاديمية بالو لايات المتحدة، وأوضحت التتائج أنه رغم التأكيد علن وجود معايير جودة التعليم، ومدني خدمتها للمجتمع والبحث العلمي خلال معايير التصنيف العالمي، إلا ان التصنيف علن أساس "

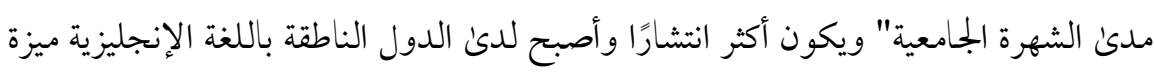
فريدة للوصول بجامعتها إلى التصنيفات القائمة على أساس الشهرة بفضل وجود جرائد عالمية إرشادية تنشر باللغة الإنجليزية. - و كشفت دراسة أحمد عبدالمطلب (• • ( ) أهمية البحث العلمي في مؤسسات التعليم الجمامعي: مدخل لتطوير الأداء البحثي في هذه المؤسسات قد أسفرت الدراسة عن نتائج كثيرة أهمها ما يلي: من أهم وظائف الجامعة إعداد القوي البشرية، وإجراء البحوث العلمية، والتنشيط الفكري 
و الثقافي، وخدمة المجتمع وتنمية البيئة، وتحقيق التعاون الدولي من أجل السلام العالمي، من أهم أهداف البحث العلمي صناعة التكنولوجيا والتقنية، والتعايش مع ظاهرة العولمة.

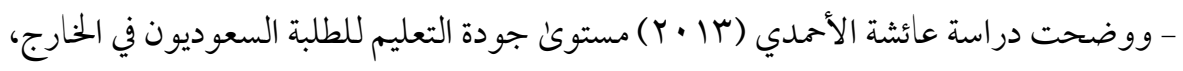
بحسب ترتيبها في تصنيفي شنغهاي وكيوأس عام (· · · ) ، وأهم الصعوبات التي تو اجهرم في سبيل الوصول لذلك، واستخدمت الباحثة المنهج الو صفي بمدخليه الوثائقي والنوعي، بالاعتماد علن بيانات كمية مستقاة من قاعدة بيانات وزارة التعليم العالي السعودي، في أربع دول هي: أمريكا، وكندا، وبريطانيا، و أستراليا، وقواعد بيانات التصنيفات الدولية للجامعات العالمية في تصنيفي شنغهاي وكيو أس (QS)، ومن أهم ما تو صلت إليه الدرا سة من نتائج وجود علاقة عكسية بين قيد الطلبة السعوديين وبين ترتيب الجامعات في تصنيفي شنغهاي وكيو أس (QS). - وسعت دراسة محمد ويح (r/ • (Y) التعرف علن أبرز التصنيفات العلمية للجامعات والمعايير التي اعتمدت عليها، مع تقديم رؤية نقدية لها، ورصد موقع الجامعات العربية من تلك التصنيفات؛ استخدم البحث المنهج الوصفي، لمعالجة مشكلة البحث من وصف وتحليل لقضية التصنيف العالمي للجامعات من حيث المفهوم والأهداف والأهمية، اقتصر البحث على (ع ) أربعة Shanghai Jiao Tong تصنيفات عالمية للجامعات وهي: تصنيف جامعة شانغهاي Times Higher University Education ولقاءات توعية بأهمية التصنيفات وفو ائدها لتطوير أداء الجامعات العربية. - واستخدمت دراسة قاسم مظلوم (10 ( + ) عدد من الأدوات منها بناء قائمة فحص (Checklist) البحث إلى أن هنالك تأثير كبير للأطراف المعنية بالعملية التعليمية من أكاديميين وطلبة وأرباب عمل ونظر اء للجامعات، إذ يعتمد التقويم في نظام (THE-QS) بصورة كبيرة علئ الاستطلاعات المعدة من قبل المنظمة للاستئناس بآرائهم. وأوصئ البحث بضرورة وضع برنامج لزيادة عدد 
الطلبة الأجانب من خلال آلية تم اقتراحها، و كذلك ضرورة استقطاب والاحتفاظ بالأستاذة من ذوي الإنتاج العلمي المنشور في بجلات عالمية معتبرة (Citation Indexed Journal) كونهم جزء مهمم من تقييم منظمة (THE- QS) ومعيارًا مهةًا في قياس نشاط الجامعة. - ووضحت دراسة كريان بكنام (10 ( T) أهمية النشر الدولي كمعيار لتصنيف الجمامعات عالميًا وفقا للمعايير المعروفة لتصنيف الجامعات في العالر، وتقدم الدراسة عرضًا لأشهر التصنيفات العالمية للجامعات، وهئ علن الترتيب: تصنيف شانجهاي، تصنيف التايمز، تصنيف الويبومتركس، تصنيف QS؛ من حيث التعريف بالتصنيف وأهدافه والمعايير التي يقوم عليها التصنيف وإبراز الوزن النسبي لكل معيار، بالإضافة إلى ذلك يتم توضيح أوائل الجامعات المُصنفة علمياً في كل تصنيف بصفة عامة وتوضيح ترتيب جامعة القاهرة بصفة خاصة سواء على إنى

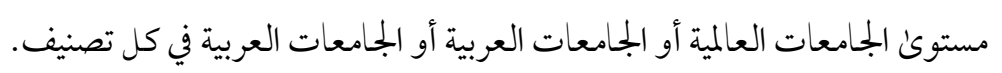
- وقدمت دراسة كريان بكنام (10 · r) عرض لأشهر التصنيفات العالمية للجامعات، وهي على الترتيب: تصنيف شانجهاي، تصنيف التايمز، تصنيف الويبومتركس، تصنيف (QS)؛ من حيث

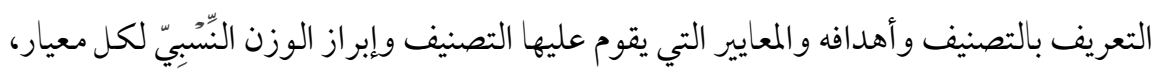

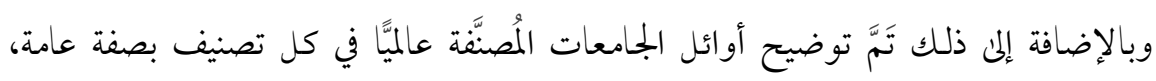
وتوضيح ترتيب الجلمعات العربية والجامعات المصرية بصفة خاصة. - وساهمت دراسة ويكفيلد وآخرين(Wakefield et al, 2015) : في تقييم إمكانية وسهولة الوصول للمعلومات ونوعيتها علن الإنترنت في الولايات المتحدة الأمريكية للتعليم الطبي لعلاج الأورام لطلاب الدراسات العليا، وتم تقييم إمكانية الوصول من خلال الجمعية الطبية الأمريكية ومجلس الاعتماد للتعليم الطبي، وتم تقييم المحتوى من خلال مقياس ليكرت، وأسفرت النتائج عن نسبة إتاحة عالية، وجودة متوسطة من جملة المعلومات المطلوبة. - وتعرفت دراسة سماح محمد (7 ( ) علن المتطلبات التربوية للارتقاء بترتيب الجامعات المصرية في التصنيفات العالمية، تتمثل مشكلة الدراسة في أن الجامعات المصرية وبخاصة جامعة المنصورة 


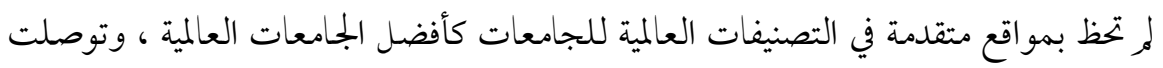

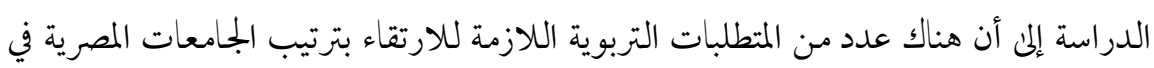

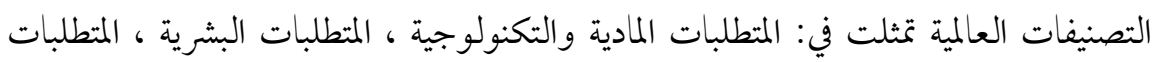
البحثية ، المتطلبات العلمية والعملية .

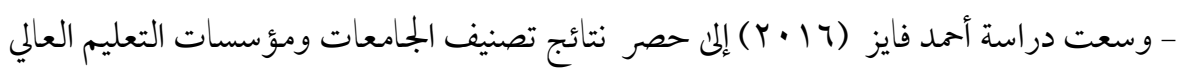

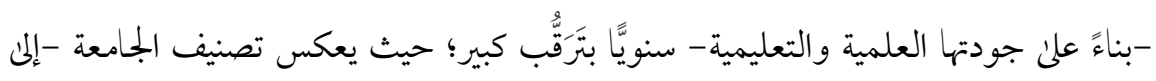

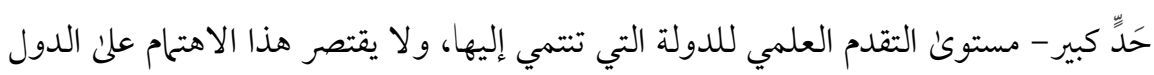

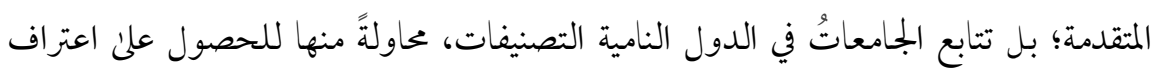

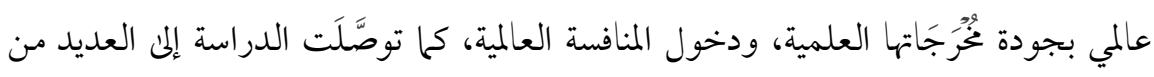

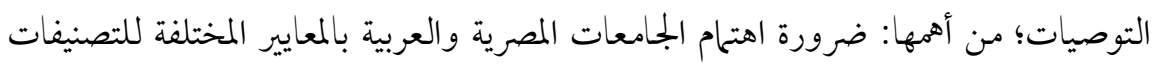

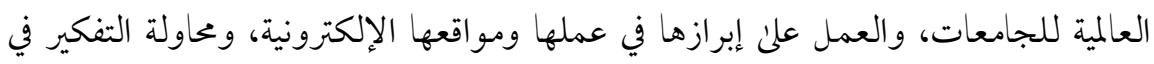

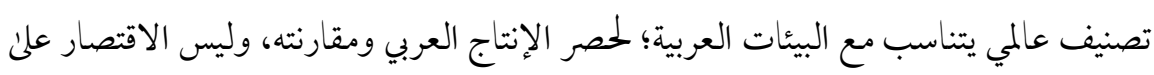
اللغة الإنجليزية فقط.

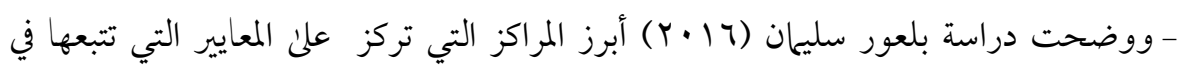

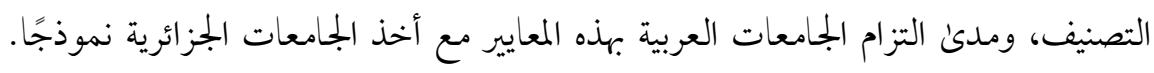

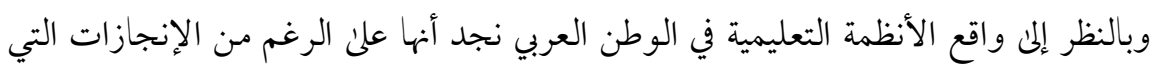

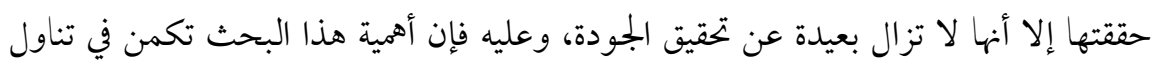

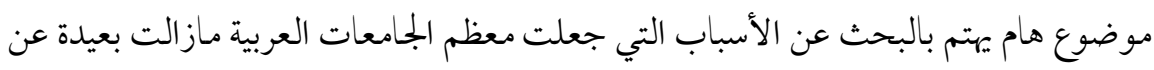

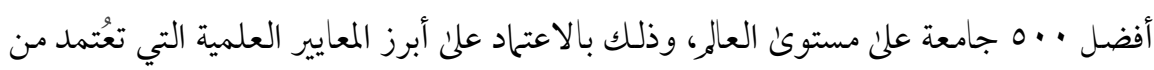
طرف المركز التي تصدر تلك التصنيفات، وصولا لتقديم بعض التوصيات التي من شأنها أن

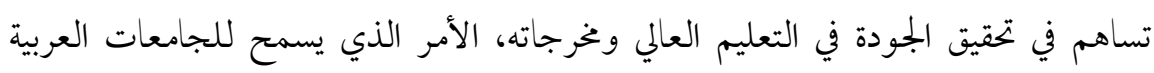

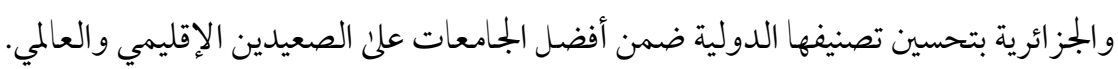


- وأبرزت دراسة هندة مدفوني (Y ( IV) المنهج الفكري الجديد القائم علن الأصول المعرفية وعلن رأسها العنصر البشري مع تبيان أهمية الاستثمار فيه عن طريق عرض آليات تنميته وتطويره، وأظهرت نتائج الدراسة أن الجامعة تلتزم بقراراتها ومسؤولياتها طويلة الأجل بتحويل رأس المال البشري من أصول (رصيد) إلى نتائج (تدفق) وتبين أن هذا التدفق يمكن قياسه من خلال المنشورات المتخصصة وإطلاق المنتجات والخدمات القائمة علن المعرفة بالإضافة إلى قياس الأداء الكلي للجامعة من خلال الاشتراك في قو اعد البيانات العالمية والحصول علن جوائز جودة الخدمة التعليمية، كما تم بناء نموذج للقياس يجمع بين مؤشرات التصنيف العالمية للجامعات ويعد التعلم الخاص ببطاقة الأداء المتوازن. ومما سبق يوضح الباحث ما يلي:

- توضيح مدئ قيمة تأثير النشر الدولي والسمعة الأكاديمية على ترتيب الجامعة الإسلامية بالمدينة المنورة في التصنيفات العالمية، حيث وضحت العديد من الدراسات السابقة أهمية التصنيفات الدولية ومدئ تأثير النشر العلمي والسمعة الأكاديمية للجامعة، وتحقيق دورها

$$
\text { الفعال بين الجامعات المحلية والدولية والدور المنوط بها. }
$$

- ويتضح مما سبق أيضًا تعدد اتجاهات الدراسات السابقة في تقديم الحصول علن التصنيفات العالمية وتحسين السمعة الأكاديمية ها حيث استهدفت دراسة ليفين وآخرون (Levin,et,al.2006)

$$
\text { وتحديد معايير الوصول إلى التصنيف العلمي }
$$

- ووضحت دراسة ليفين و وآخرون (Levin,et,al.2006) معنى أن تكون جامعة مصنفة عالميًا، وتحديد معايير الوصول إلى التصنيف العالمي، وعرضت دراسة عادل الهاشم

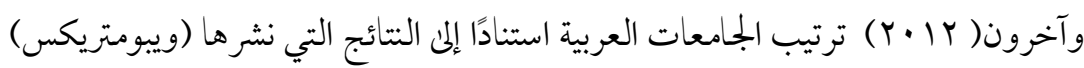
(Webometrics) السعوديون في الخارج، بحسب ترتيبها في تصنيفي شنغهاي وكيوأس، وتعرفت دراسة محمد 
ويح (rا • r) التعرف علن أبرز التصنيفات العلمية للجامعات والمعايير التي اعتمدت عليها، مع تقديم رؤية نقدية لها، ورصد موقع الجلمعات العربية من تلك التصنيفات، ووضعت دراسة قاسم مظلوم(10) عدد من الأدوات منها بناء قائمة فحص (Checklist) ومقابلات شخصية مع عدد من المعنيين بالجودة ومدئ الاحتفاظ وضرورة استقطاب والاحتفاظ بالأستاذة من ذوي الإنتاج العلمي المنشور في مجلات عالمية معتبرة. - ووضحت دراسة كريمان بكنام (10 · ( ) أهمية النشر الدولي كمعيار لتصنيف الجمامعات عالميا وفقا للمعايير المعروفة لتصنيف الجامعات في العالم، وتقدم الدراسة عرضا لأشهر : (Wakefield et al, التصنيفات العالمية للجامعات، وساهمت دراسة ويكفيلد وآخرين (2015 في تقييم إمكانية وسهولة الوصول للمعلومات ونوعيتها علن الإنترنت في الولايات

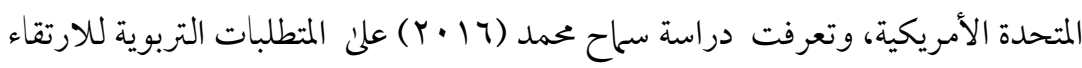
بترتيب الجامعات المصرية في التصنيفات العالمية ، تتمثل مشكلة الدراسة في أن الجامعات المصرية وبخاصة جامعة المنصورة له تحظ بمو اقع متقدمة في التصنيفات العالمية للجامعات كأفضل الجامعات العالمية، وسعت دراسة أحمد فايز (17 + (Y) إلى حصر نتائج تصنيف الجحامعات ومؤسسات التعليم العلي -بناءً علن جودتها العلمية والتعليمية، ووضحت

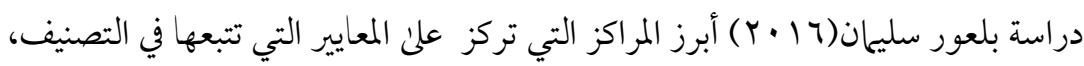

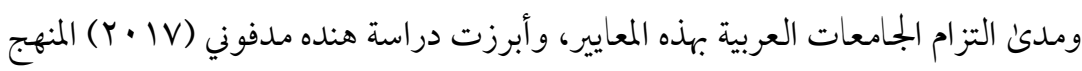
الفكري الجديد القائم علن الأصول المعرفية وعلن رأسها العنصر البشري مع تبيان أهمية الاستثمار فيه عن طريق عرض آليات تنميته وتطويره، وتوضيح جو انب الصعوبة،، وسعت

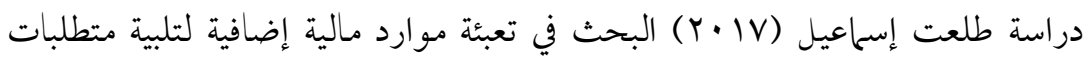
التصنيفات العالمية للجامعات. 
واستخدم البحث الحلاي المنهج الوصفي وهذا ما اتفق مع أغلب الدراسات السابقة، وانفرد البحث الحالي بالكشف عن تأثير النشر الدولي والسمعة الأكاديمية علن ترتيب الجامعة الإسلامية بالمدينة المنورة في التصنيفات العالمية. مشكلة البحث

يعد موضوع التصنيفات العالمية من العناصر الأساسية الذئ يساعد الجامعات علئ تواجدها علن الساحات العلمية والأكاديمية حيث الإنتاج العلمي والسمعة الأكاديمية، وهذا أيضًا يزيد الجامعة الإسلامية بالمدينة المنورة انتشارًا وقوة بين الجامعات المحلية والعربية والدولية لمكانتها المحلية

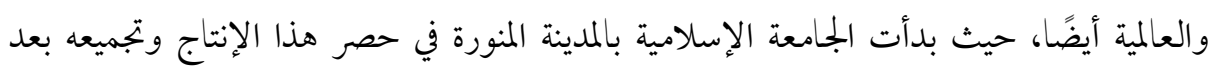

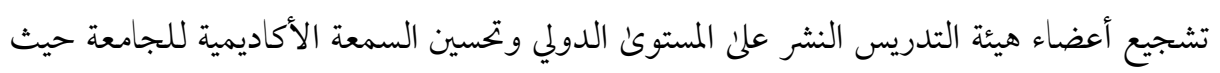
جمعت الجامعة بين العلوم الشرعية والعلوم الأخرى (العلوم، الحاسب، الهندسة، السنة التحضيرية للكليات العلمية).

وتتحدد مشكلة البحث الحالية في قلة عدد الدراسات والأبحاث للجامعة الإسلامية ودخوها التصنيفات الدولية، حيث إن بها طلاب من مستوئ العالم وأيضًا أعضاء هيئة تدريس، ولذلك ينبغي وضع هذه البيانات عبر البوابات الإلكترونية ودخول الجامعة محط التصنيف الدولي وذلك من خلال توجه الجامعة لخططها المستقبلية.

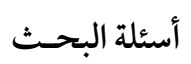
وفي ضوء ما سبق تحاول الدراسة الحالية الإجابة على التساؤلات الآتية: ا - ما أهم التصنيفات العالمية للجامعات التي ظهرت بها الجامعة الإسلامية؟ وما المعايير التي

$$
\text { تعتمد عليها؟ }
$$

Y- - ما موقع الجامعة الإسلامية بالمدينة المنورة عالميًا وعربيًا ومحليًا بالتصنيفات؟

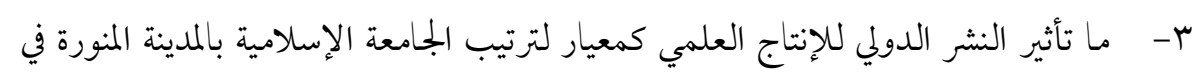
التصنيفات العالمية؟

ع - ما السمعة الأكاديمية للجامعة الإسلامية بالمدينة المنورة التي تتمثل في التصنيفات العالمية؟ http://dx.doi.org/10.29009/ijres.2.2.5 


$$
\text { استهدفت البحث الحلالي ما يلي: }
$$

- - الكشف عن مدئ تأثير التصنيفات العالمية للجامعات التي ظهرت بها الجامعة الإسلامية

$$
\text { بالمدينة المنورة. }
$$

- التعرف علن موقع الجامعة الإسلامية بالمدينة المنورة عالميًا وعربيًا ومحليًا بالتصنيفات.

- الكشف عن السمعة الأكاديمية للجامعة الإسلامية بالمدينة المنورة في ضوء التصنيفات

$$
\text { العالمية. }
$$

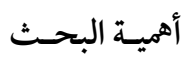

$$
\text { وتتلخص أهمية البحث فيما يلي: }
$$

- يساعد علن النهوض في عملية التنمية والتطوير للجامعة وحصولها علن مراكز متقدمة

$$
\text { وشر اكات عالمية ذات التصنيف العالي. }
$$

- - تساعد على جودة التعليم والحصول علن ترتيب عالمي للجامعة في ضوء التصنيفات الدولية.

$$
\text { - - تحقيق أعلى درجات لمستوي الجودة في مخرجات التعلم المتميزة في ضوء خبرات دولية. }
$$

Times News ، QS،Webometrics) - تسليط الضوء علن التصنيفات الدولية المتعددة ومنها -

\section{.(Education}

\section{حـدود البحــث}

تقتصر الدراسة علن عرض أشهر التصنيفات العالمية للجامعات ومنها:

أولاً : تصنيف شنغهاي: Academic Ranking of world Universities by.

ثانيًا: تصنيف ويب ماتركس: Webometrics: World Universities' Ranking on the web by

.Cybermetrics Lab

ثالثًا: تصنيف كيو اس ستار (QS Stars).

رابعًا: تصنيف التايمز (Times) لترتيب جامعات التعليم العلاي.

\section{http://dx.doi.org/10.29009/ijres.2.2.5}


- وتقتصر الدراسة من حيث التعريف بالتصنيف وأهدافه والمعايير التي يقوم عليها التصنيف

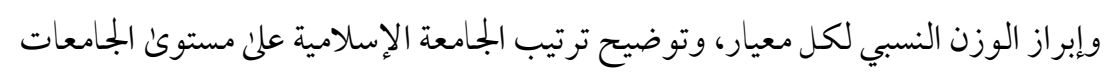
العالمية أو الجامعات العربية أو الجلمعات المحلية في كل تصنيف.

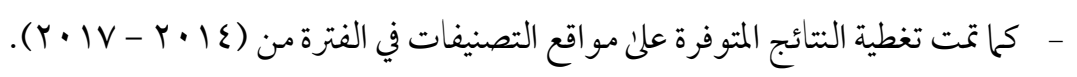

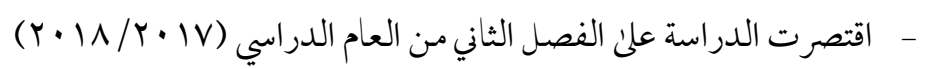

$$
\text { مــواد وأدوات البحــث }
$$

اعتمد الباحث علن قاعدة بيانات SCOPUS و Scival ، وقام بعدد من الإجراءات المنهجية

(www.scopus.com - www.scival.com)

- - قاعدة البيانات واختيار حقل البحث Affiliation Search و تدوين مصطلح البحث Islamic University of Madinah

$$
\text { - - - تحديد من النتائج الوثائق الخاصة بالجامعة الإسلامية وكلياتها. }
$$

- - حصر بيانات النشر والسمعة الأكاديمية للجامعة الإسلامية بالمدينة المنورة، وقد دون

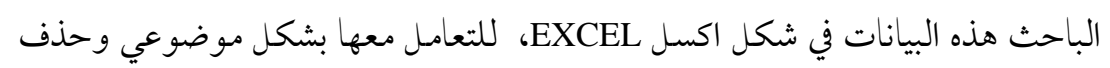

$$
\text { المكرر منها؛ لإجراء التحليلات الإحصائية لكافة البيانات المخزنة. }
$$

مصطلحات البحث

النشر الدولي

يشار إليه إجرائيًا: بأنه نشر نتائج الأبحاث العلمية في الدوريات العلمية العالمية المحكمة من

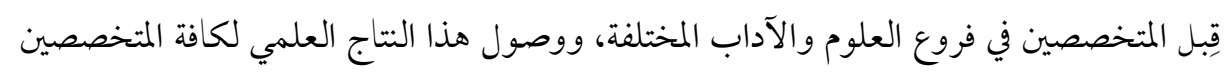

و الباحثين للاستفادة منها في كافة المواقع الرسمية وإبرازه هذه الأعمال عبر مو اقعها الإلكترونية. 


\section{السمعة الأكاديمية}

يشار إليها إجرائيًا: تحقيق الأهداف الواضحة لتقييم الأداء الداخلي والخارجي للجامعة بحيث ترك الانطباع والصورة الذهنية الإيجابية في الداخل والخارج بتميز الأداء وجودة المخرجات.

\section{التصنيفات العالمية للجامعات}

ويشار إجرائيًا بأنها بجموعة من الإجراءات المنظمة في البحث والتقييم توضح ترتيب الجامعات حيث المستون العلمي والأكاديمي ، وذلك من خلال بجموعة من المعايير المعتمدة وتوضيح الوزن النسبي ها أو تقييم المو اقع الإلكترونية في ضوء بعض المعايير الخاصة لكل تصنيف.

$$
\text { منهجيسـة البحـث وإجراءاته }
$$

منهج البحث: استخدم الباحث المنهج الوصفي، وذلك لرصد ما يراه من معلومات حول بعض الجامعات ومدئ تقدمها، وبين الجامعة الإسلامية وكيفية التطوير للوصول النى كافة التصنيفات العالمية وتقدم الجامعة. • عينة البحث: الجامعة الإسلامية حيث النشر -السمعة الأكاديمية إجراءات البحث: للإجابة علي أسئلة البحث والتحقق من صدق فروضه اتبع الباحث

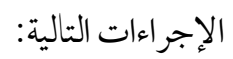

- - الاطلاع علن الدراسة السابقة والبحوث المتعلقة بموضوع البحث. - - مشكيل اطار نظري للبحث

- الدخول علئ المو اقع التي تهتم بالتصنيفات العالمية للجامعات، ومنها:

أو لاً : تصنيف شنغهاي: Academic Ranking of world Universities by ثانيًا: تصنيف ويب ماتركس: 'Webometrics: World Universities' Ranking .on the web by Cybermetrics Lab ثالثًا : تصنيف ستار كيواس(QS Stars) . رابعًا: تصنيف التايمز (Times) لترتيب جامعات التعليم العالي. 


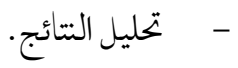

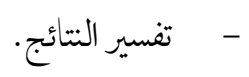

$$
\begin{aligned}
& \text { - }
\end{aligned}
$$

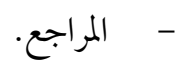

$$
\begin{aligned}
& \text { للإجابة علن أسئلة البحث والتحقق من صدق فروضه اتبع الباحث الإجراءات التالية: }
\end{aligned}
$$

السؤال الأول: ما أهم التصنيفات العالمية للجامعات التي ظهرت بها الجامعة الإسلامية؟ وتوصلت الدراسة إلى أن: - n

الجامعة الإسلامية بالمدينة المنورة قد ظهرت في العديد من التصنيفات الدولية المعروفة منها مـا يعتمد في مؤشراته علن السمعة الأكاديمية والأخر يعتمد في مؤشراته علن النشر العلمي وفيما يلي لمحة عن هذه التصنيفات ومعايير تقيمها:

\section{أولاً : تصنيف شنغهاي: Academic Ranking of world Universities by SJTU}

هو الترتيب الأكاديمي للجامعات العالمية Academic Ranking of World) Universities ولقبه بالاختصار (ARWU) وهو تقرير يصدر من مركز بحوث الجامعات العالية العالمية التابعة لمعهد بحوث التربية والتعليم العالمية في (جياو تونغ) بشانغهاي. وقدصدر لأول مرة في شهر يونيو من عام r...r، ويقوم ARWU باختيار أول (500) جامعة كل سنة من بين الجامعات

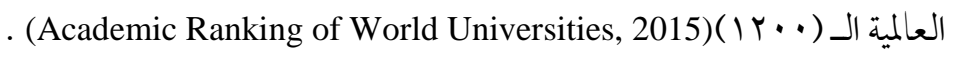

$$
\text { المعايير التي يقوم عليه تصنيف شنغهاي: }
$$

تعتمد طريقة تصنيف شنغهاي علن أربعة معايير رئيسة هي Academic Ranking Of World

:(Universities, 2015)

$$
\text { - - المعيار الأول: جودة التعليم، و المعيار الثاني: نوعية أعضاء هيئة التدريس وجودتهم }
$$

- والمعيار الثالث: الإنتاج البحثي، في مجلتي العلوم والطبيعة (Nature\& Science) ) وفي دليل

$$
\text { النشر العلمي، ودليل النشر للعلوم، ودليل النشر للفنون والعلوم الإنسانية. }
$$


Dr. Elnaggar, Khaled M.

Volume (2) No. (2) 2019

- - والمعيار الرابع: الإنجاز الأكاديمي، ويقاس بالدرجات التي تحصل عليها الجامعة في المعايير الثلاثة الأولى نسبة إلى عدد الكوادر الأكاديمية في الجامعة.

$$
\text { جدول (7) معايير تصنيف جامعة جايو تونج شانغهاي }
$$

\begin{tabular}{|c|c|c|}
\hline النسبة & 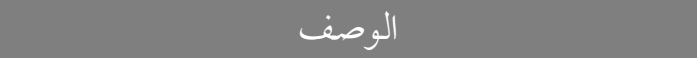 & 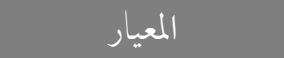 \\
\hline$\% 10$ & الخريبين الفائزين بجائزة نوبل أو جو ائز فيلد للرياضيات & جودة التعليم \\
\hline$\% 20$ & أعضاء هيئة التدريس الفائزين بجائزة نوبل أو جوائز فيلد للرياضيات & \multirow{3}{*}{ نوعية أعضاء هيئة التدريس } \\
\hline$\% 20$ & كثرة الرجوع أو الاستشهاد بأبحاثهم & \\
\hline$\% 20$ & الأبحاث المنشورة في أفضل بجلات الطبيعة و العلوم & \\
\hline$\% 20$ & الأبحاث المنشورة في أفضل بجلات الطبيعة والعلوم & \multirow[b]{2}{*}{ خرجات البحث العلمي } \\
\hline$\% 20$ & الأبحاث المذكورة في كشاف العلوم الاجتحاعية و الكشاف المرجعي & \\
\hline$\% 10$ & أداء الجحامعة بالنسبة لحجمها & حجم الجحمعة \\
\hline$\% 100$ & 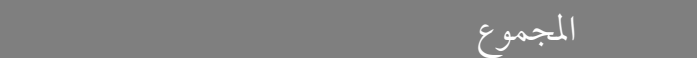 & \\
\hline
\end{tabular}

ونلاحظ من جدول السابق أن المعايير المعتمدة لقياس كفاءة الجامعات وجودتها في هذا التصنيف هي أربعة تتمثل في (جودة التعليم / نوعية أعضاء هيئة التدريس/ مخرجات البحث

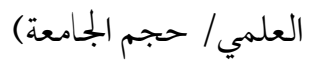

ثانيا: تصنيف ويب ماتركس Webometrics: World Universities' Ranking on the web by

Cybermetrics Lab

هو تصنيف عالمي مشهور يصدر عن فريق بحث يتبع اكبر مركز أبحاث إسباني (CSIC) ويرتبط بوزارة التربية والتعليم في مدريد، ويهدف إلى تشجيع نشر المعلومات علن مواقع الجامعات، وهو يصنف الجامعات بحسب المعلومات عنها وذات العلاقة بها والمتوفرة في مو اقعها علن الأنترنت. وهذا التصنيف يصدر منذ عام (ع + ·r) بشكل نصف سنوي (كانون الثاني / يناير وتموز/ يوليو)،

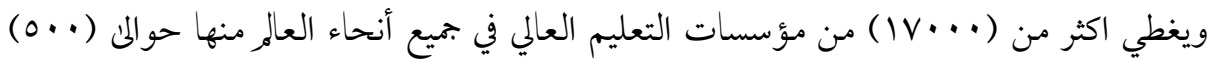




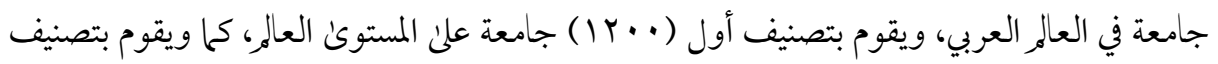
أول ( . . ( ) جامعة حسب القارة أو حسب المنطقة) (Ranking web of the university, 2015) . ويعد الهدف لرئيس للترتيب تعزيز نشاط البحث والنشر العلمي للجامعات علن الإنترنت،

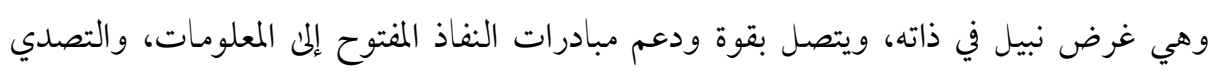

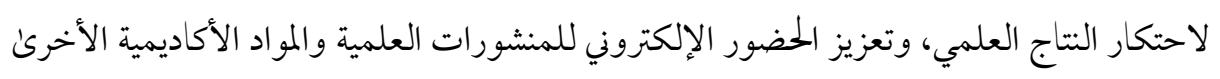

.(Webometrics,2011)

المعايير التي يقوم عليها التصنيف

يقوم التصنف علن أساس أن نشاطات أي جامعة تظهر في مواقعها الإلكترونية، ويستند هذا

التصنف علن أربعة معايير تشكل معا تقييل للجامعة، وهي (Ranking web of the university, 2015) :

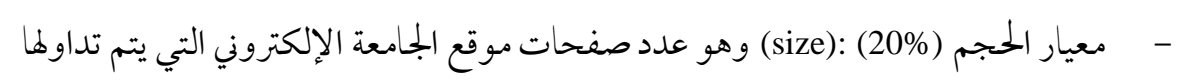

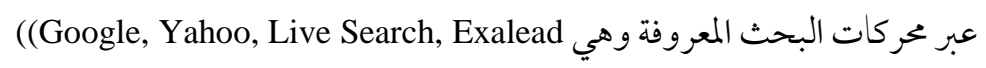

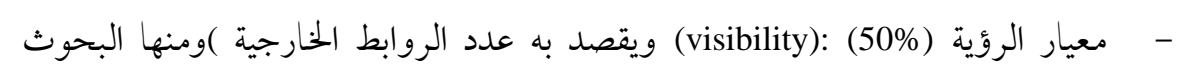

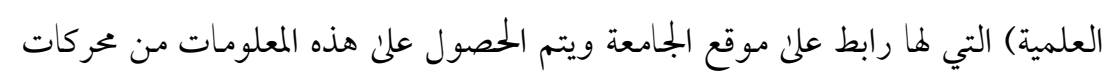
البحث.(Yahoo Search, Live Search, Exalead) - معيار الملفات الغنية (rich files15\%) :حيث يتم حساب عدد الملفات "الإلكترونية"

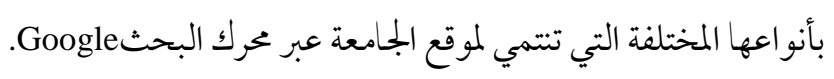

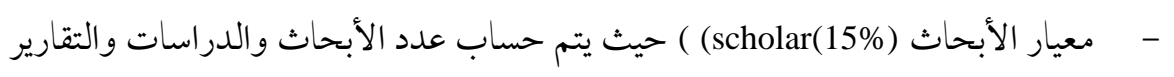

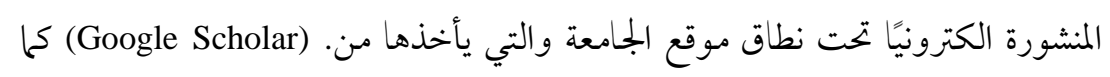

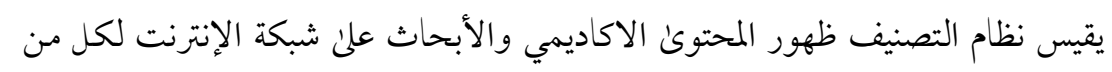

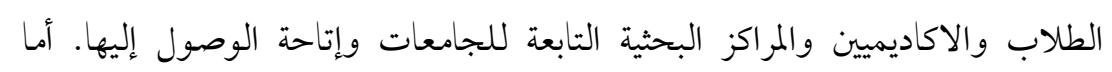

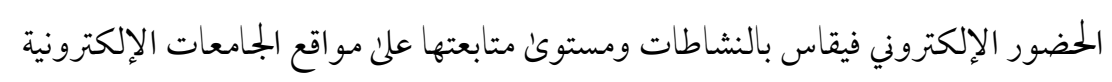

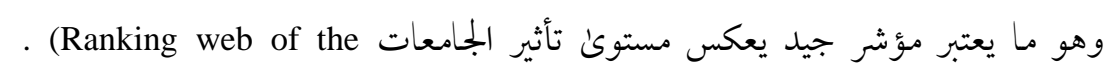
university, 2018) 
Dr. Elnaggar, Khaled M.

Volume (2) No. (2) 2019

جدول (V) تصنيف ويبومتريكس

\begin{tabular}{|c|c|c|}
\hline النسبة & الوصف & المعيار \\
\hline$\%$. & حجم الموقع & الحجم \\
\hline$\% 10$ & الملفات الثرية & \multirow{2}{*}{ خرجات البحث } \\
\hline$\% 10$ & علماء جوجل & \\
\hline$\%$ & الرؤية للر ابط & الأثر \\
\hline
\end{tabular}

ثالثًا : تصنيف ستار كيواس (QS Stars)

لقد نشأ تصنيفا الكيو اس عام ع · · مج، وتأسست الشركة التي أنشأته عام •99 199، وكان مقرها في لندن) (Baccini, et al, 2015) .

تم تصميم نظام (QS) نجوم للسماح للمؤسسات للتألق، بغض النظر عن حجمها وشكلها ورسالتها. ويتم منح نجوم يعتمد علن التدقيق من قبل وحدة الاستخبارات (QS) بتصنيفات نشرت منفصلة لكل معيار من المعايير الثمانية. المعايير التي يقوم عليها التصنيف ستارز كيو اس (QS Stars) : في بداية نشأة هذا التصنيف كان يقوم على ستة معايير فقط، Baccini, et al, 2015 ثم زاد

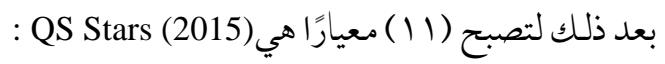
- - البحث: بمعنى تقييم جودة البحوث في أوساط الأكاديميين والإنتاجية (أي عدد من الأبحاث المنشورة)، الاستشهادات (أي البحوث والأوراق التي تم الرجوع إليها من قبل الأكاديميين الآخرين) والجو ائز (مثل جوائز نوبل أو ميداليات فيلدز).

- - - التدريس: فالدور الرئيسي للجامعة هو تنشئة أفضل العقول للغد، وإعداد الجيل القادم من الأكاديميين، ومنتجي البحوث المحتملين. تقييم جودة التدريس، وجمع التقييات الطلابية من خلال مسوح وطنية للطلاب، وزيادة معدل الدراسة ونسبة أعضاء هيئة التدريس للطالب.

\section{http://dx.doi.org/10.29009/ijres.2.2.5}


- - - التوظيف: توظيف الدراسات العليا يشمل اكثر قوة أكاديميا، مع التركيز علن "الجاهزية

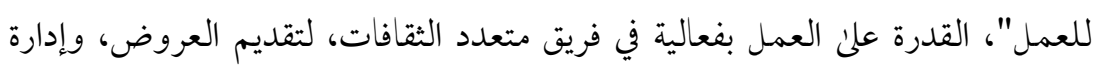

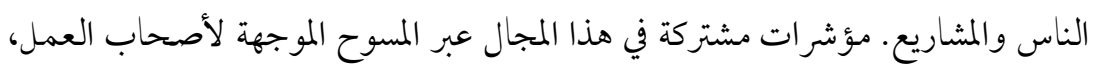

$$
\text { ومعدلات توظيف الخريين ودعم الخدمات المهنية. }
$$

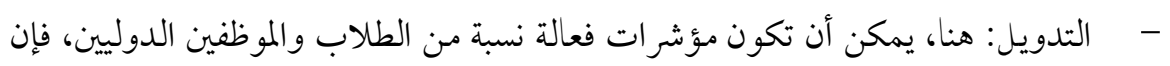

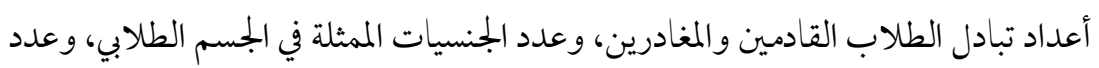
وقوة الشراكات الدولية مع الجمعات الأخرى ووجود المرافق الدينية.

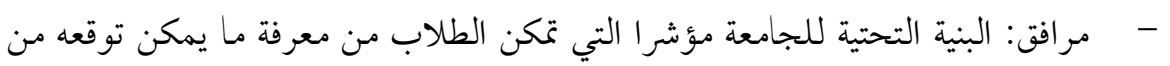

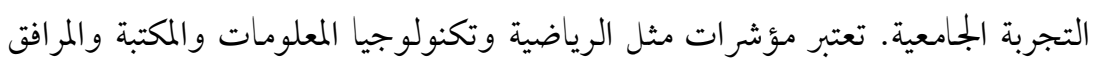
الطبية، وكذلك عددمن طلاب المجتمعات ضمن هذا المعيار. - الإنترنت / التعلم عن بعد: هذه الفئة تنظر إلن مؤشرات مختلفة مثل الخدمات مدات الطلابية والتكنولوجيا، وسجل حافل، والمشاركة الكلية طالب، التفاعل بين الطالب، والتزام الأنترنت وسمعة الجمامعة.

- - المشاركة: يقيس مدئ الجدية التي تأخذ الخطوبة جامعة التزاماتها تجاه المجتمع من خلال

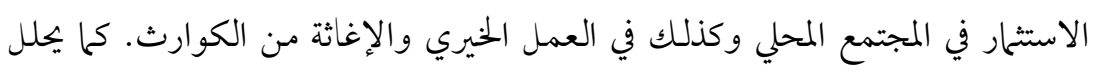

$$
\text { الإقليمية وتتميه رأس المال البشري والوعي للبيئة. }
$$

- الابتكار : الابتكار، والناتج من أنشطة الجمامعات والنتائج علن الاقتصاد و المجتمع و الثقافة،

$$
\text { وأصبح متزايد الأهمية للجامعات. }
$$

- م ثقافة: مؤشرات فعالة هي عدد من الحفلات الموسيقية والمعارض التي تنظمها المؤسسة، وعددمن الاعتمادات والجوائز الثقافية والاستثمار الثقافي.

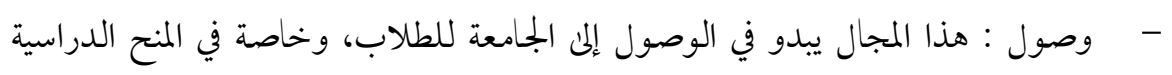

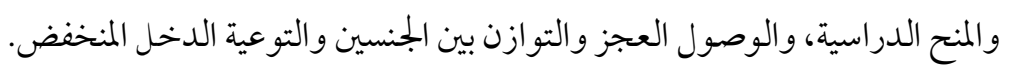


- - معايير متخصصة: التميز في بجال ضيق هو مطالبة صحيحة لمصاف العالمية والكفاءة في الجولة. وتهدف هذه المعايير إلى تقديم الائتحان حيث إنها المناسب. هذه الفئة تنظر في منح

$$
\text { التراخيص و التصنيف الانضباط. }
$$

$$
\text { جدول (^) تصنيف كيو أس( التايمز) البريطاني للجامعات }
$$

\begin{tabular}{|c|c|c|}
\hline النسبة & 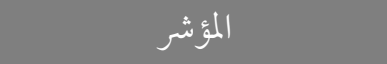 & 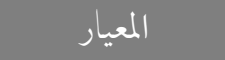 \\
\hline $40 \%$ & تقويم الأقران(Peer Review) & \multirow{2}{*}{ جودة البحث } \\
\hline $20 \%$ & معدل النشر لكل عضو هيئة التدريس & \\
\hline $10 \%$ & تقويم جهات التوظيف & توظيف الخريجين \\
\hline $5 \%$ & أعضاء هيئة التدريس العامليين & \multirow{2}{*}{ النظرة العالمية للجامعة } \\
\hline $5 \%$ & الطلبة العالميون & \\
\hline $20 \%$ & نسبة الطلبة إلى أعضاء هيئة التدريس & جودة التعليم \\
\hline $100 \%$ & \multicolumn{2}{|c|}{ المجموع } \\
\hline
\end{tabular}




$$
\text { رابعًا تصنيف التايمز لترتيب جامعات التعليم العالي }
$$

(The Times Higher Education World University Rankings) هذا التصنيف مدعوم من تومسون رويترز ويقوم علئ تصنيف الجمامعات بناء على (rا ( ) مؤشر موزعة علن خمسة محاور ويتم الموثوقة من قبل الطلاب والأكاديميين وقادة الجامعة والصناعة والحكومات .

(Times Higher Education World University Rankings, 2015)

$$
\text { المعايير التي يقوم عليها تصنيف التايمز: }
$$

يقوم هذا التصنيف على (r ا ) مؤشر موزعة على خمسة بجالات رئيسة هي:

- - التدريس: بيئة التعلم (بقيمة · بـ/ من درجة تصنيف عام)

$$
\text { - - البحث: حجم والدخل والسمعة (بقيمة ·r\%) }
$$

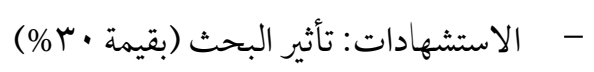

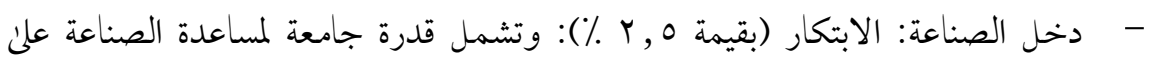
الابتكارات والاختراعات والاستشارات ومقدار الدخل الذي تجنيه الجامعة من المؤسسات الصناعية. ويشير الابتكار "إلى أي مدئ استعداد الشركات لدفع ثمن البحوث وقدرة الجامعة علن استقطاب التمويل في السوق التجاري التنافسي. - - النظرة الدولية: الموظفين والطلبة والبحوث (بقيمة ه v٪)، ويشمل هذا المجال ثلاث

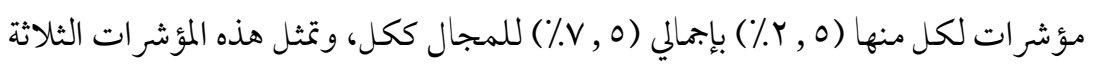
فيها يلي: هذه الفئة تنظر إلى التنوع في الحرم الجامعي، وإلى أي درجة يتعاون مع الزملاء الأكاديميين الدوليين علن المشاريع البحثية و قدرة الجامعات علن جذب الطلاب الجامعيين وطلاب الدراسات العليا من جميع أنحاء الكوكب و يقاس هذا العامل من نسبة الدولية

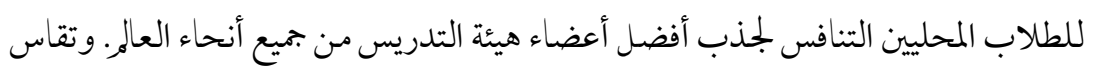
بنسبة من الموظفين الدوليين إلى الموظفين المحليين. - نسبة من إجمالي منشورات بجلة بحوث الجامعة التي بها مؤلف دولي واحد مشارك علئ الأقل ((Times Higher Education World University Rankings, 2015) 
Dr. Elnaggar, Khaled M.

Volume (2) No. (2) 2019

جدول (9) تعاريف التايمز Times لتصنيف الجامعات

\section{التعريف}

المعيار

هو تقويم مبني علنى أراء ما يزيد عن ( . . 7) من الأكاديميين و العلماء في تخصصات خختلفة ينتشرون حول العالم يقومون بتقييم البرامج الأكاديمية لكل جامعة في خمس ججالات أساسية، العلوم الطبيعية والعلوم الهندسية والعلوم الحيوية والعلوم الإنسانية والعلوم

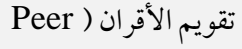

(Review الاجتماعية. ولا يسمح لهؤلاء الأكاديميين بالمشاركة في تقييم جامعاتهم. يتوزع هؤلاء الأكاديميون على تخصصات مختلفة في دول متعددة ولا زالوا نشطين علميا، ويتم التعرف على أراء وتقويم جهات التوظيف وأرباب العمل لمستوي خريجي الجمامعات المصنفة من حيث: -طاقتهم الإبداعية والابتكارية. - إمكاناتهم التحليلية. -القدرات اللغوية التي يمتلكونها. -سلوكياتهم الوظيفية. - الناتج المادي الملموس في أداء الواجبات الوظيفية للخريجين. نسبة الأساتذة الدوليين في الجامعة الخاضعة للتقييم للعدد الكلي. فالجامعات الناجحة لابد أن تجذب أفضل الأساتذة من مختلف أرجاء العالم. نسبة الطلاب الدوليين في الجامعة الخاضعة للتقييم بالنسبة لمجموع الطلبة الكلي. فالجامعات الناجحة لابد أن تجذب أفضل الطلاب.

وتحسب من خلال نسبة عدد الطلاب إلى عدد الأساتذة في الجامعة، وتمثل مدي التزام الجامعة الناجحة بالمهمة التعليمية. البحوث التي ينشر ها أساتذة الجامعة مـن حيث: نسبة الإشارة لبحوثهم في البحوث العالمية الأخرى بالنسبة لكل أستاذ بالجامعة. الأثر العالمي للبحوث المنفذة في ظل الجامعة. ويعد هذا المعيار عالميا بالغ الأهمية في مجال البحوث التقنية والعلمية. ورغم أهميته البالغة فقد حمل وزنا أقل من سابقه، وذلك كي لا يؤثر بشكل بالغ في تقييم الجامعات التي لا تشكل التخصصات الهندسية و التقنية العصب الرئيس في برابجها، حيث إن الإشارة للبحوث في المجالات الإنسانية والاجتماعية تعد أقل إلى حدماعن تلك في المجالات العلمية الأخرىن.
تقويم جهات التوظيف

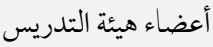

العالميين

الطلبة العالميين

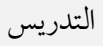

الإشارة إلى أبحاث المؤسسة التعليمية
الطلبة وأعضاء هيئه 
السؤال الثاني: ما موقع الجامعة الإسلامية بالمدينة المنورة عالميًا وعربيًا ومحليًا بالتصنيفات؟ وتأتى أهمية هذا النوع من التقيم إلى الدور الحيوي والمتنامي للمواقع الالكترونية في نشر الأبحاث العلمية، وغيرها من المواد الأكاديمية، وهو ما يعرف بـ (E-journals)، علاوة على السهولة والسرعة، والكلفة المنخفضة، وإمكانية الاطلاع في كل وقت، وأي مكان، كما تشمل تلك المواقع نشاطات أعضاء هيئة التدريس والباحثين ، والتواصل بينهم ويين طلابهم، وتؤدى محصلة تلك العوامل المي إثراء أداء الجامعة، وإبراز مكانتها، أو ما يعرف بـ Global performance and visibility of the university.

\section{ترتيب الجامعة الإسلامية بالمدينة المنورة في تصنيف ويبوميتر كس (Webometrics)} لقد تأثر الترتيب الأكاديمي لموقع الجامعة علن الصعيد المحلي والعالمي. ومن هنا جاء في يناير 1 ا · التوجه الإستراتيجي نحو إنشاء عمادة التعليم عن بعد بموجب قرار بجلس التعليم العالي رقم

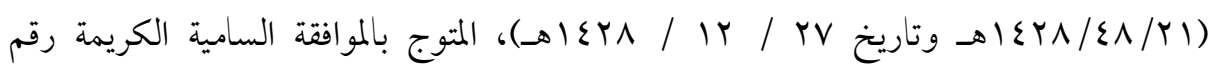

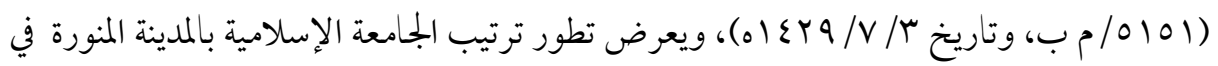

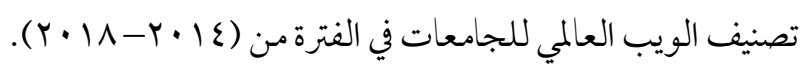
جدول (11) تصنيف ويب ماتريكس webometrics للجامعات

\begin{tabular}{|c|c|c|c|c|c|c|c|c|}
\hline $\mathrm{N}$ & Universities & $\begin{array}{c}\text { World } \\
\text { Ranking } \\
\text { التصنيف العالمي }\end{array}$ & $\begin{array}{c}\text { Continental } \\
\text { Ranking } \\
\text { التصنيف }\end{array}$ & $\begin{array}{c}\text { Country } \\
\text { Rank } \\
\text { ترتيب البلد }\end{array}$ & $\begin{array}{l}\text { Presen } \\
\text { ce } \\
\text { الحضور }\end{array}$ & $\begin{array}{c}\text { Impa } \\
\text { ct } \\
\text { التأثير }\end{array}$ & $\begin{array}{c}\text { Openne } \\
\text { ss } \\
\text { الانفتاح }\end{array}$ & $\begin{array}{c}\text { Excellen } \\
\text { ce } \\
\text { التفوق }\end{array}$ \\
\hline 1 & King Saud University & 424 & 1 & 1 & 282 & 836 & 1012 & 255 \\
\hline 2 & $\begin{array}{l}\text { Islamic University of Al } \\
\text { Madinah }\end{array}$ & 5119 & 180 & 21 & 6606 & 4482 & 3958 & 5777 \\
\hline 3 & Ain Shams University & 1522 & 14 & 5 & 2331 & 6043 & 1529 & 793 \\
\hline 4 & University of Jordan & 1220 & 10 & 1 & 58 & 2473 & 765 & 1294 \\
\hline 5 & University of Liverpool & 231 & 84 & 21 & 1370 & 359 & 256 & 159 \\
\hline 6 & Boston University & 43 & 38 & 36 & 218 & 52 & 19 & 67 \\
\hline 7 & $\begin{array}{c}\text { University of Western } \\
\text { Australia }\end{array}$ & 136 & 8 & 8 & 581 & 189 & 171 & 115 \\
\hline 8 & $\begin{array}{c}\text { National University of } \\
\text { Colombia }\end{array}$ & 629 & 15 & 1 & 88 & 483 & 903 & 942 \\
\hline
\end{tabular}




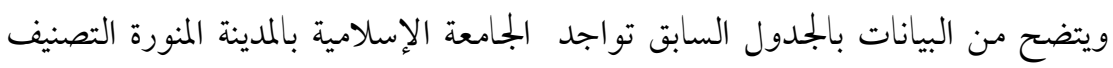

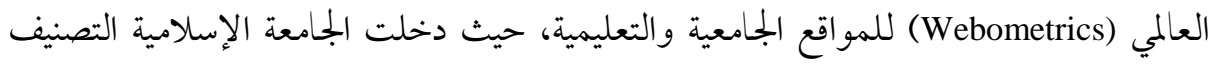

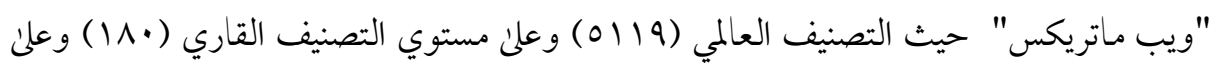

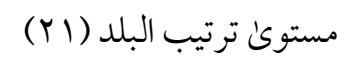

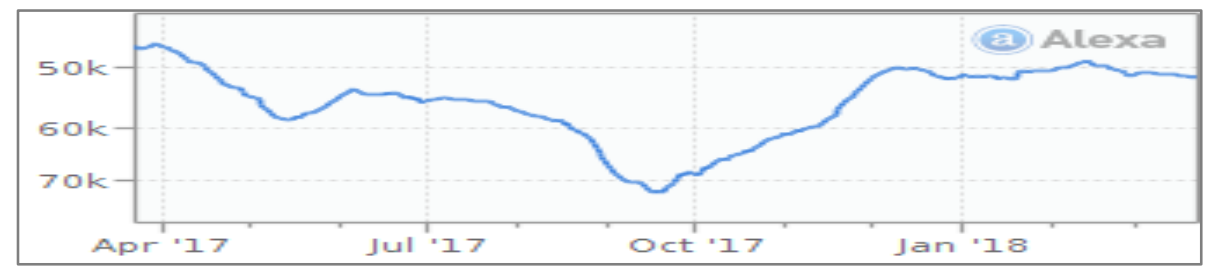

شكل (1 ): تطور الترتيب العلمي لمؤشر ويب ماتريكس للجامعات

ومن خلال النتائج السابقة والاطار النظري للبحث والدراسات السابقة يمكن أن تعزين

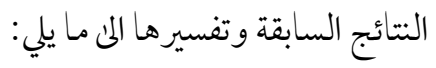
- - مداثة الأقسام والكليات العلمية المتوفرة بالجامعة الإسلامية بالمدينة المنورة - - مداثة علمة البحث العلمي والمهام الموكلة واليها. - - توجه الجمامعة الإسلامية في بداية عهدها بالعلوم الشرعية فقط دون غيرها - - - توجه الجمعة المى الاعتماد الأكاديمي والبرابجي مؤخرًا.

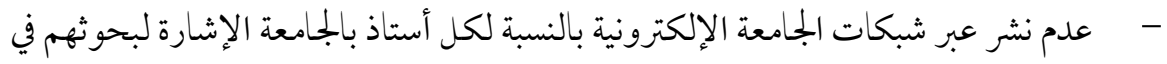

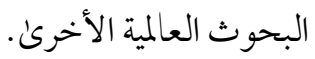




\section{1. تصنيف شنغهاي: Academic Ranking of world Universities by}

ويتضح تصنيف شنغهاي في الجلدول التالم:

$$
\text { جدول (r ) معايير تصنيف جامعة جايو تونج شانغهاي }
$$

\begin{tabular}{|c|c|c|}
\hline 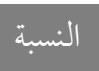 & 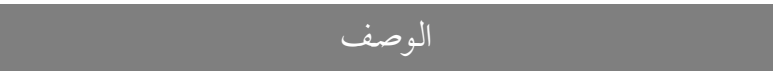 & 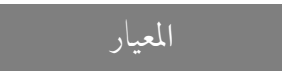 \\
\hline$\% 10$ & الخرييجين الفائزين بجائزة نوبل أو جو ائز فيلد للرياضيات & جودة التعليم \\
\hline$\% 20$ & أعضاء هيئة التدريس الفائزين بجائزة نوبل أو جو ائز فيلد للرياضيات & \multirow{3}{*}{ نوعية أعضاء هيئة } \\
\hline$\% 20$ & كثرة الرجوع أو الاستشهاد بأبحاثهم & \\
\hline$\% 20$ & الأبحاث المنشورة في أفضل مجلات الطبيعة والعلوم & \\
\hline$\% 20$ & الأبحاث المنشورة في أفضل بجلات الطبيعة والعلوم & \multirow[b]{2}{*}{ مخرجات البحث العلمي } \\
\hline$\% 20$ & الأبحاث المذكورة في كشاف العلوم الاجتحاعية و الكشاف المرجعي & \\
\hline$\% 10$ & أداء الجامعة بالنسبة لحجمها & 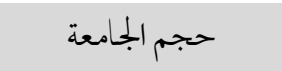 \\
\hline$\% 100$ & 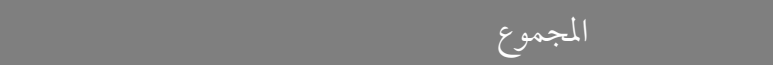 & \\
\hline
\end{tabular}

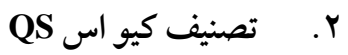

تتضمن المعايير العالمية للتصنيف 9 مؤشرات، رئيسية في مقدمتها السمعة الأكاديمية (• ب٪)،

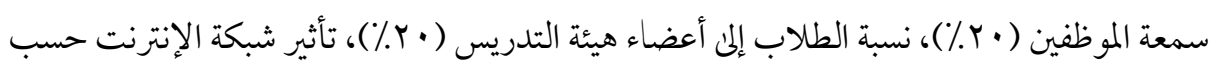

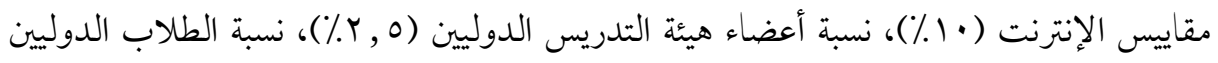
(0, Y\%)، نسبة الموظفين من حملة الدكتوراه (0\%)، اقتباسات البحثية للأوراق البحثية (0\%)، الإسهامات البحثية لكل عضو هيئة تدريس حسب نظام قواعد بيانات scoups (0٪). 
Dr. Elnaggar, Khaled M.

Volume (2) No. (2) 2019

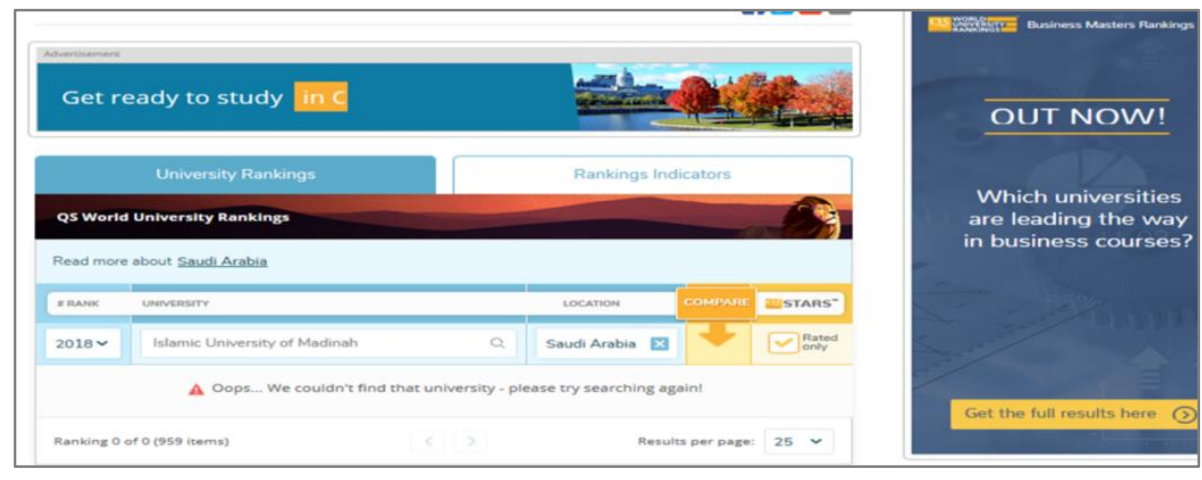

جدول (r ا )ترتيب الجامعة الإسلامية بالمدينة المنورة في تصنيف (QS) للجامعات

\begin{tabular}{|c|c|c|c|c|}
\hline$r \cdot 1 \wedge$ & $r \cdot I V$ & $r \cdot 10$ & $r \cdot 1 \varepsilon$ & ترتيب الجلامعة \\
\hline- & - & - & - & الإسلامية \\
\hline YYI & rVV & $r \varepsilon 9$ & ror & الملك سعود \\
\hline IVT & 119 & YYO & r17 & الملكك فهد للبترول \\
\hline YTV & $r \wedge \mu$ & ع & rq. & الملك عبد العزيز \\
\hline
\end{tabular}

ويتضح من الجدول (r) (I) عدم تواجد الجلمعة الإسلامية بالمدينة المنورة في تصنيف (QS) للججامعات.

ومن خلال النتائج السابقة والإطار النظري للبحث والدراسات السابقة يمكن أن تعزى النتائج السابقة وتفسيرها إلى ما يلي:

- - قلة المنشورات على مو اقع الجامعة الإسلامية لبعض المعلومات الدقيقة حول النشر لأعضاء هيئة التدريس.

- عدم تحديد موقع الجامعة الإلكتروني كمحركات بحثية مرتبطة بالجامعة الإسلامية. - عدم حساب عدد الملفات "الإلكترونية الخاصة بالجامعة الإسلامية بالمدينة المنورة. - - عدم الاهتحام بنشر عدد الأبحاث والدراسات والتقارير المنشورة الكترونيًا علن موقع

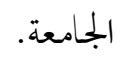

http://dx.doi.org/10.29009/ijres.2.2.5 
- قلة البيانات المنشورة علن موقع الجامعة لحساب علمة البحث العلمي (https://iu.edu.sa/Page/index/21449) - ق قلة نطاق موقع الجامعة الإسلامية والتي يأخذها منGoogle Scholar الذئ يساعد علن التصنيف وظهور المحتوى الأكاديمي والأبحاث علن شبكة الإنترنت لكل من الطلاب والأكاديميين. السؤال الثالث: ما تأثير النشر الدولي للإنتاج العلمي كمعيار لترتيب الجامعة الإسلامية بالمدينة المنورة

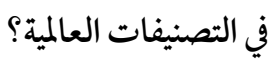
Ranking Web ) للنشر الدولي للإنتاج العلمي تأثيره في تصنيف الويب للجامعات العالمية (World Universities المجلات الدولية عالية التأثير كما هو موضح بالجدول مجلة التايمز. جدول (10) تصنيف كيو أس( التايمز) البريطاني للجامعات

\begin{tabular}{|c|c|c|}
\hline النسبة & 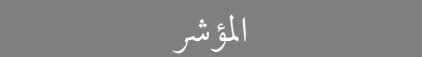 & 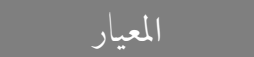 \\
\hline $40 \%$ & تقويم الأقران(Peer Review) & \multirow{2}{*}{ جودة البحث } \\
\hline $20 \%$ & معدل النشر لكل عضو هيئة التدريس & \\
\hline $10 \%$ & تقويم جهات التوظيف & توظيف الخرييين \\
\hline $5 \%$ & أعضاء هيئة التدريس العامليين & \multirow{2}{*}{ النظرة العالمية للجامعة } \\
\hline $5 \%$ & الطلبة العالميون & \\
\hline $20 \%$ & نسبة الطلبة إلى أعضاء هيئة التدريس & جودة التعليم \\
\hline $100 \%$ & \multicolumn{2}{|c|}{ المجموع } \\
\hline
\end{tabular}

ومن خلال الجدول السابق يتضح أن جودة البحث (• ع.٪) ومن خلال البحث والدراسة حول موقع الجامعة الإسلامية في البحث العلمي حسب تصنيف التايمز من خلال ما يلي: 
1- تصنيف الجامعة الإسلامية وفق بجلة التايمز.

جدول رقم (7imes) (17) تصنيفات الجامعات وفق بجلة تايمز

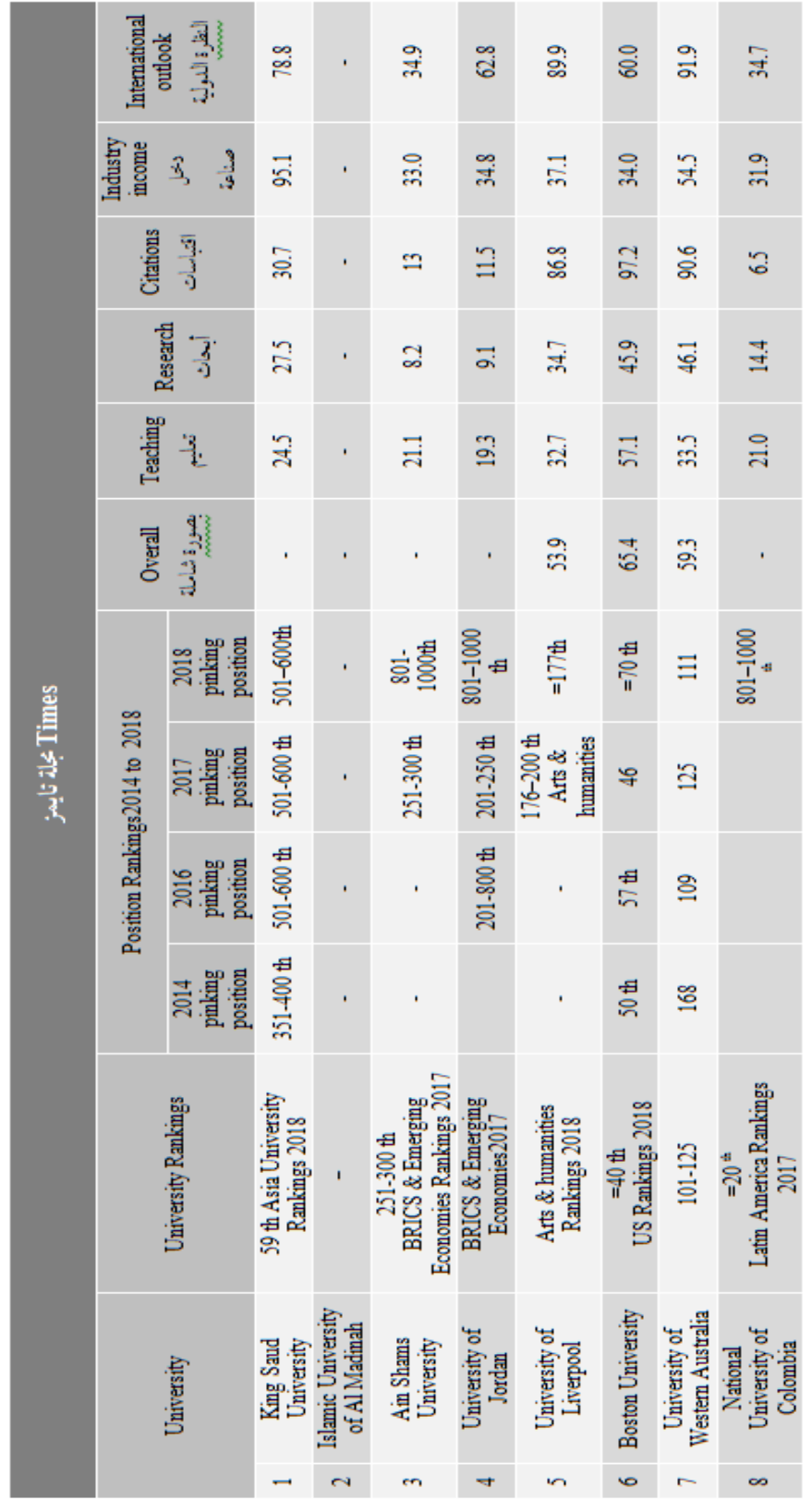

http://dx.doi.org/10.29009/ijres.2.2.5 
ويتضح من الجمدول السابق اختفاء الجامعة الإسلامية من النشر للبحث العلمي وفق بجلة تايمز ومقارنة بالجامعات المحلية لا يوجد تواجد وكذلك مقارنة بالجامعات الدولية لا يوجد مؤشرات. ومن خلال النتائج السابقة والاطار النظري للبحث والدراسات السابقة يمكن أن تعزىن النتائج السابقة وتفسيرها المى ما يلي: - - عدم اتباع ثقافة تقويم الأقران بشكل صحيح أسوة بالجامعات المحلية والجامعات العالمية. - قلة نسبة إجمالي منشورات مجلة بحوث الجامعة الإسلامية التي بها مؤلف دولي واحد مشارك

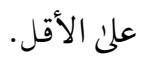
- - الكليات العلمية مستحدثة في الجلمعة الإسلامية حيث يتوفر فقط ( كلية العلوم- كلية

$$
\text { الحاسب - كلية الهندسة). - ملك. }
$$

- عدم تفعيل الموقع الالكتروني للجامعة حيث نسبة الإشارة لبحوثهم في البحوث العالمية الأخرىن بالنسبة لكل أستاذ بالجامعة. (https://iu.edu.sa/Page/index/21449) - في الآونة الأخيرة لمريتم اعلان علن مواقع الجامعة بعض البيانات التي تساعد المختصين على التنافس الدولي كحساب نسبة عدد الطلاب إلى عدد الأساتذة في الجامعة، مدي التزام الجامعة الناجحة بالمهمة التعليمية.

ما السمعة الأكاديمية للجامعة الإسلامية التي تتمثل في التصنيفات العالمية؟ للسمعة الأكاديمية دور كبير في التصنيفات العالمية حيث تؤثر نتائجها علن السمعة الأكاديمية للجامعة، وعلان مدئ قدرتها علن استقطاب الطلبة، حيث توفر هم المعلومات التي يحتاجون اليها لاختبار الجامعة التي تلبي احتياجاتهم علن أفضل وجه، والدفع نحو الوصول إلى مصاف العالمية، وتحقيق المزيد من الشفافية، وتشجيع الجامعات علن تحسين نوعية برابجها وتطوير جودة الأداء، ويقوم هذا التصنيف علي با مؤشر موزعة علن خمسة مجالات رئيسة هي: (Times Higher Education World University Rankings, 2015) 
Dr. Elnaggar, Khaled M.

Volume (2) No. (2) 2019

$$
\begin{aligned}
& \text { - التدريس: بيئة التعلم (بقيمة • r٪٪ من درجة تصنيف عام) } \\
& \text { - البحث: حجم والدخل والسمعة (بقيمة ·r\%) } \\
& \text { - الاستشهادات: تأثير البحث (بقيمة • ابم\%) }
\end{aligned}
$$

- دخل الصناعة: الابتكار (بقيمة O, O \%): وتشمل قدرة جامعة لمساعدة الصناعة علئ الابتكارات والاختراعات والاستشارات ومقدار الدخل الذي تجنيه الجامعة من المؤسسات الصناعية. ويشير الابتكار "إلى أي مدئ استعداد الشركات لدفع ثمن البحوث وقدرة

$$
\text { الجامعة على استقطاب التمويل في السوق التجاري التنافسي. }
$$

- النظرة الدولية: الموظفين والطلبة والبحوث (بقيمة ه, ه٪): ويشمل هذا المجال ثلاث

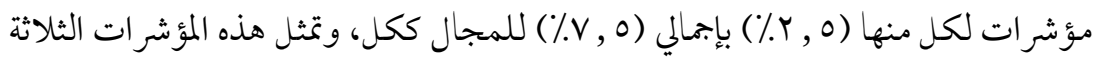
فيما يلي: هذه الفئة تنظر إلى التنوع في الحرم الجامعي، وإلى أي درجة يتعاون مع الزملاء الأكاديميين الدوليين علن المشاريع البحثية و قدرة الجامعات علن جذب الطلاب الجامعيين وطلاب الدراسات العليا من جميع أنحاء الكوكب و يقاس هذا العامل من نسبة الدولية للطلاب المحليين التنافس لجذب أفضل أعضاء هيئة التدريس من جميع أنحاء العالم. ومن خلال عرض ما يلي تتضح السمعة الأكاديمية للجامعة الإسلامية بالمدينة المنورة في ضوء التصنيفات العالمية. 
جدول رقم (IV) السمعة الأكاديمية للجامعة الإسلامية التي تتمثل في التصنيفات العالمية الجمعات وفق بجلة تايمز (Times)

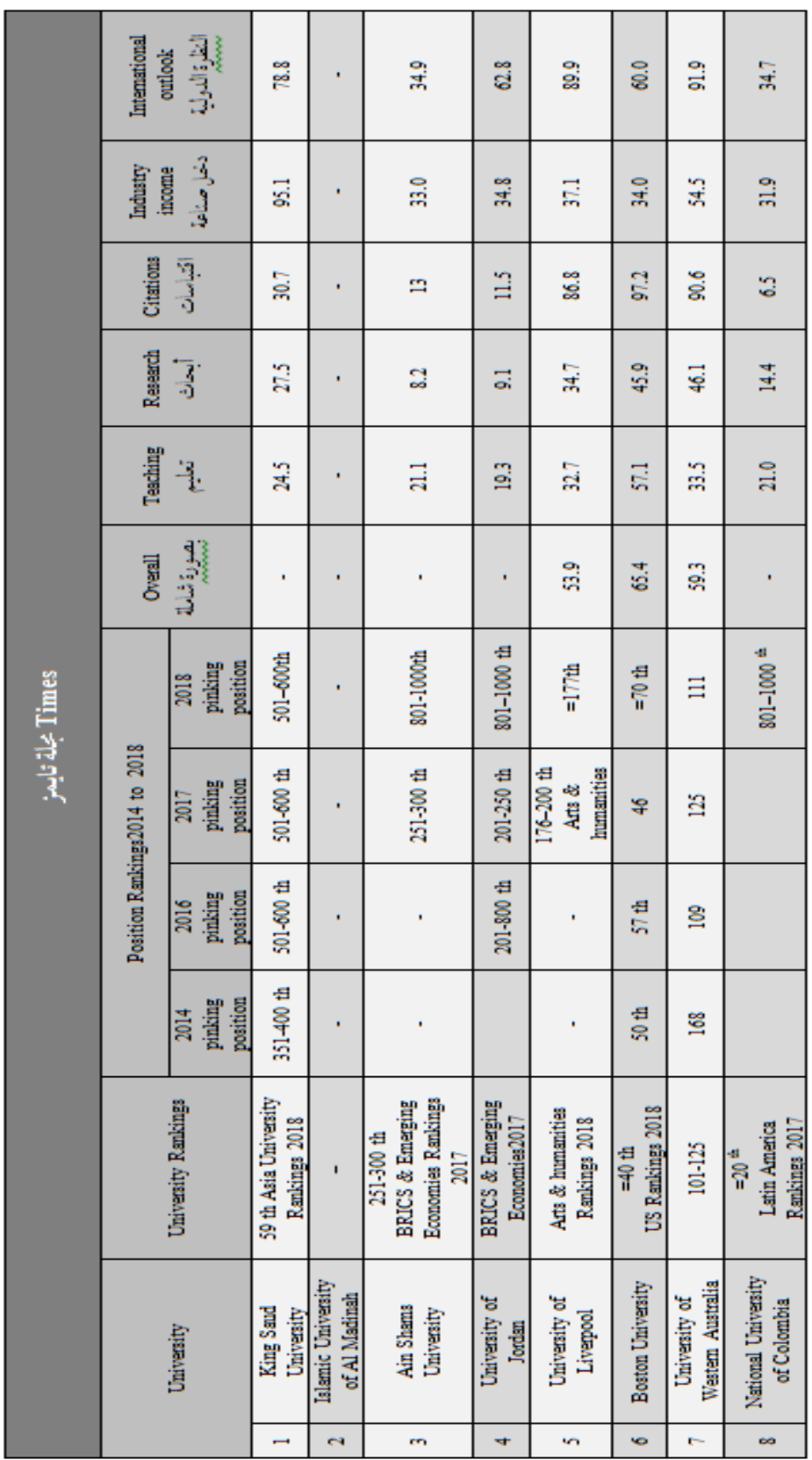


ويتضح من الجدول السابق اختفاء الجامعة الإسلامية حيث السمعة الأكاديمية وفق مجلة

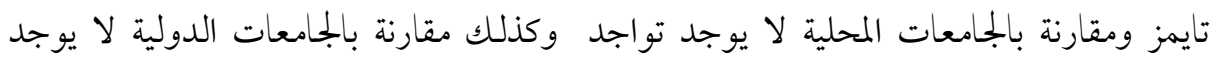

ومن خلال النتائج السابقة والاطار النظري للبحث والدراسات السابقة يمكن أن تعزىن

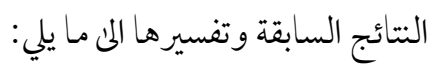
- قلة المؤشرات العامة والفرعية المتعلقة بالجامعة الإسلامية عبر المواقع الإلكترونية أسوة بالجامعات المحلية والدولية الأخرىن. - قلة نسب الاستشهاد بمو اقع الجمامعة الإسلامية بالمدينة المنورة.

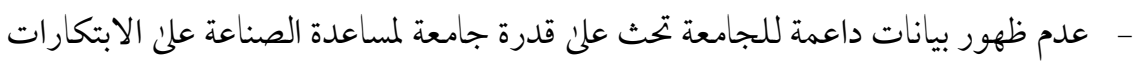

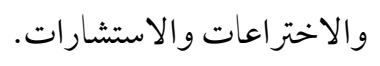

- - من خلال مواقع الجامعة الالكتروني له يظهر قدرة الجامعة علن استقطاب التمويل في السوق

$$
\text { التجاري التنافسي. }
$$

- عدم تحديد وتوضيح نسبة عدد الموظفين الدوليين إلن الموظفين المحليين ومدئ المشاركة في

$$
\text { المشاريع البحثية. }
$$


أولاً : تصنيف شنغهاي: Academic Ranking of world Universities by

وهو الترتيب الأكاديمي للجامعات العالميةAcademic Ranking of World) Universities) ، ولقبه بالاختصار (ARWU) وهو تقرير يصدر من مركز بحوث الجامعات العالية العالمية التابعة لمعهد بحوث التربية والتعليم العالمية في (جياو تونغ) بشانغهاي تعتمد طريقة تصنيف شنغهاي على أربعة معايير رئيسة هي)Academic Ranking Of World Universities, 2015)

$$
\text { جدول (11) معايير تصنيف جامعة جايو تونج شانغهاي }
$$

\begin{tabular}{|c|c|c|}
\hline 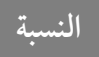 & 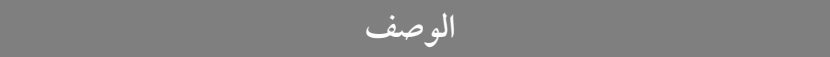 & 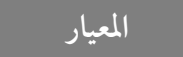 \\
\hline$\% 10$ & الخرييين الفيائزين بجائزة نوبل أو جو ائز فيلد للرياضيات & 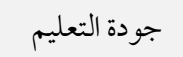 \\
\hline$\% 20$ & أعضاء هيئة التدريس الفائزين بجائزة نوبل أو جو ائز فيلد للرياضيات & \multirow{3}{*}{ نوعية أعضاء هيئة } \\
\hline$\% 20$ & كثرة الرجوع أو الاستشهاد بأبحاثهم & \\
\hline$\% 20$ & الأبحاث المنشورة في أفضل بجلات الطبيعة والعلوم & \\
\hline$\% 20$ & الأبحاث المنشورة في أفضل بجلات الطبيعة والعلوم & \multirow{2}{*}{ خرجات البحث } \\
\hline$\% 20$ & الأبحاث المذكورة في كشاف العلوم الاجتماعية و الكشاف المرجعي للعلوم الموسع & \\
\hline$\% 10$ & أداء الجامعة بالنسبة لحجمها & حجم الجمامعة \\
\hline$\% 100$ & 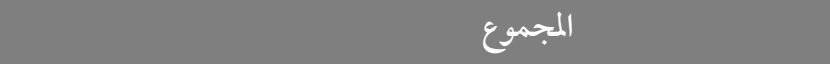 & \\
\hline
\end{tabular}

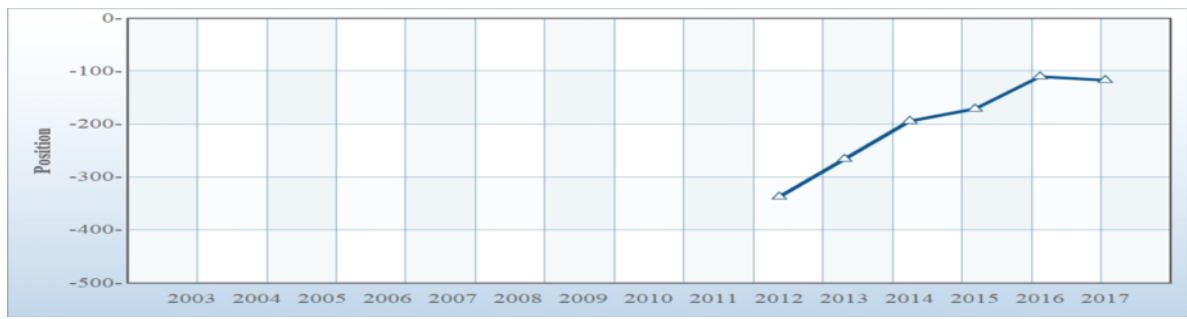

شكل (r): تطور الترتيب العالمي لمؤشر شانغهاي للجامعات بالمملكة العربية السعودية (King Abdulaziz University) 
Dr. Elnaggar, Khaled M.

Volume (2) No. (2) 2019

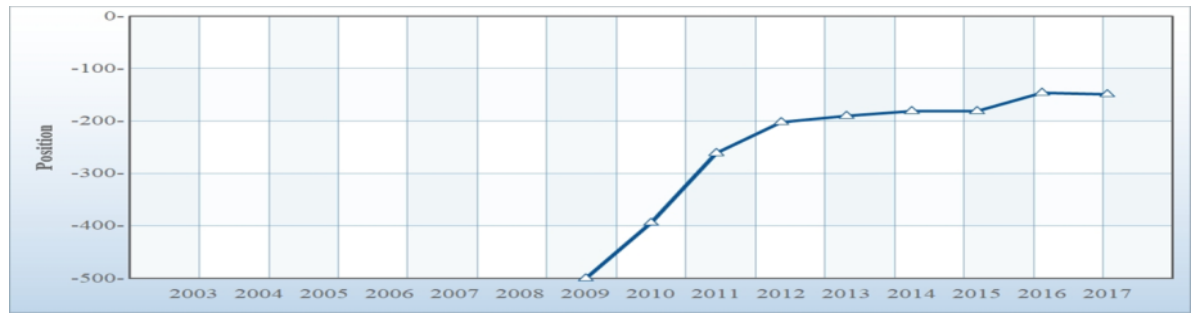

شكل (r): تطور الترتيب العالمي لمؤشر شانغهاي للجامعات بالمملكة العربية السعودية (King Saud University)

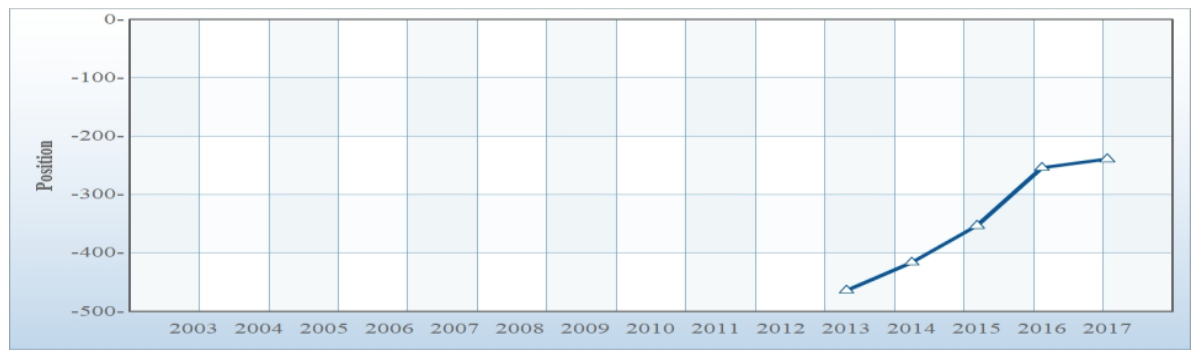

شكل (ع): تطور الترتيب العالمي لمؤشر شانغهاي للجامعات بالمملكة العربية السعودية King Abdullah University of

Science and Technology)

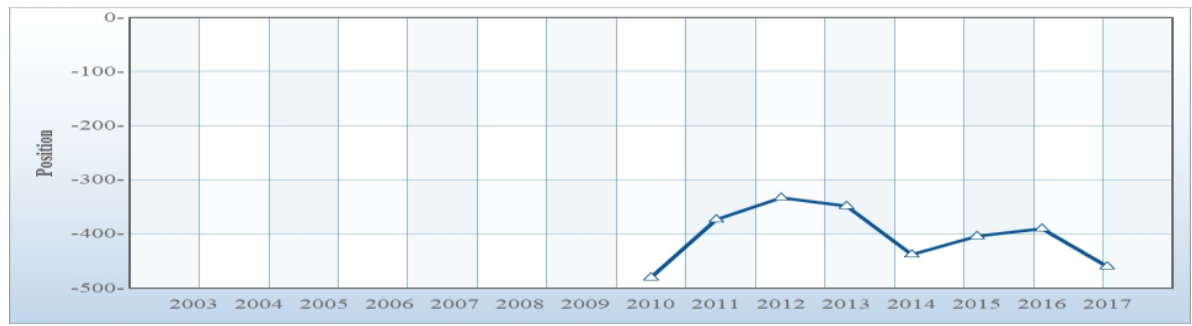

شing Fahd University of شكل (0): تطور الترتيب العالمي لمؤشر شانغهاي للجامعات بالمملكة العربية السعودية

(Petroleum \& Minerals) 
ثانيًا: تصنيف ويب ماتركس Webometrics: World Universities' Ranking on the web

by Cybermetrics Lab

\begin{tabular}{|c|c|c|c|c|c|c|c|c|}
\hline $\mathrm{N}$ & Universities & $\begin{array}{c}\text { World } \\
\text { Ranking } \\
\text { التصنيف }\end{array}$ & $\begin{array}{c}\text { Continental } \\
\text { Ranking } \\
\text { التصنيف }\end{array}$ & $\begin{array}{c}\text { Country } \\
\text { Rank } \\
\text { ترتيب }\end{array}$ & $\begin{array}{l}\text { Presence } \\
\text { الحضور }\end{array}$ & $\begin{array}{c}\text { Impact } \\
\text { التأثير }\end{array}$ & $\begin{array}{l}\text { Openness } \\
\text { الانفتاح }\end{array}$ & $\begin{array}{c}\text { Excellence } \\
\text { التفوق }\end{array}$ \\
\hline 1 & $\begin{array}{l}\text { King Saud } \\
\text { University }\end{array}$ & 424 & 1 & 1 & 282 & 836 & 1012 & 255 \\
\hline 2 & $\begin{array}{c}\text { Islamic } \\
\text { University of } \\
\text { Al Madinah }\end{array}$ & 5119 & 180 & 21 & 6606 & 4482 & 3958 & 5777 \\
\hline 3 & $\begin{array}{l}\text { Ain Shams } \\
\text { University }\end{array}$ & 1522 & 14 & 5 & 2331 & 6043 & 1529 & 793 \\
\hline 4 & $\begin{array}{c}\text { University of } \\
\text { Jordan }\end{array}$ & 1220 & 10 & 1 & 58 & 2473 & 765 & 1294 \\
\hline 5 & $\begin{array}{l}\text { University of } \\
\text { Liverpool }\end{array}$ & 231 & 84 & 21 & 1370 & 359 & 256 & 159 \\
\hline 6 & $\begin{array}{c}\text { Boston } \\
\text { University }\end{array}$ & 43 & 38 & 36 & 218 & 52 & 19 & 67 \\
\hline 7 & $\begin{array}{c}\text { University of } \\
\text { Western } \\
\text { Australia }\end{array}$ & 136 & 8 & 8 & 581 & 189 & 171 & 115 \\
\hline 8 & $\begin{array}{c}\text { National } \\
\text { University of } \\
\text { Colombia }\end{array}$ & 629 & 15 & 1 & 88 & 483 & 903 & 942 \\
\hline
\end{tabular}

ويتضح من الجمدول السابق تواجد الجلامعة الإسالامية بالمدينة المنورة حيث السمعة الأكاديمية

وفق بجلة تايمز ومقارنة بالجامعات الأخرىن وفق التصنيف العالمي حظيت على المرتبة (5119)،

و التصنيف القاري حظيت (180)، ووفق ترتيب البلد حظيت (21)، ووفق الحضور حظيت (6606)

ووفق التأثير حظيت (4482)، ووفق الانفتاح حظيت (3958) ووفق التفوق حظيت (5777).

ومن خلال النتائج السابقة والاطار النظري للبحث والدراسات السابقة يمكن أن تعزى'

النتائج السابقة وتفسيرها المى مـا يلي:

- بداية التو جه بالخطة الاستراتيجية الجلديدة وفقر رؤية • ب•

- التطوير الشامل حيث الاعتماد المؤسسي والبرابجي وفق خطة الجـامعة.

- - إقامة العديد من الندوات التي تحث على تغير النظرة الدولية للجامعة الإسلامية من علوم

شرعية فقط المى فتح كليات علمية أخرىئ مثل ( كلية العلوم - الحاسب - الهندسة)

http://dx.doi.org/10.29009/ijres.2.2.5 
Dr. Elnaggar, Khaled M.

Volume (2) No. (2) 2019

- زيادة نسبة إجمالي منشورات منسوبي الجامعة الاسمية في الفترة الأخيرة نظرًا لاستحداث

$$
\text { بعض النظم الإدارية والأكاديمية. }
$$

- التوجه في الفترة الأخيرة المى استقطاب أفضل الأساتذة من مختلف أرجاء العالم. - استقطاب أفضل الطلاب من الدول الأخرى نسبة المى عدد الطلاب المحلين

ثالثًا : تصنيف ستار كيواس (QS Stars)
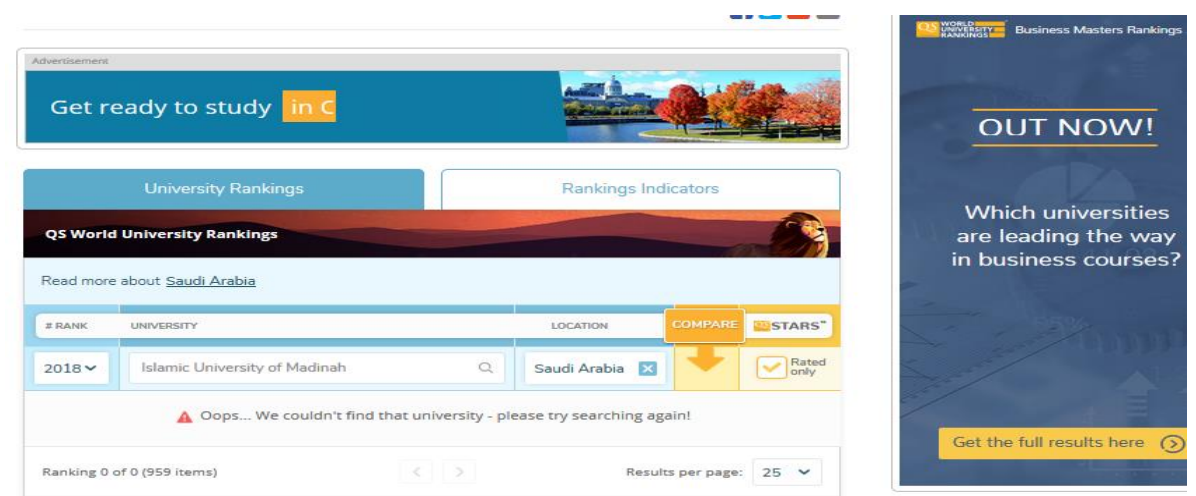

ومن خلال تتبع موقع (QS Stars): لم تظهر الجامعة الإسلامية وفق هذا التصنيف أسوة بباقي الجامعة العربية والمحلية. 
رابعًا تصنيف التايمز لترتيب جامعات التعليم العالي

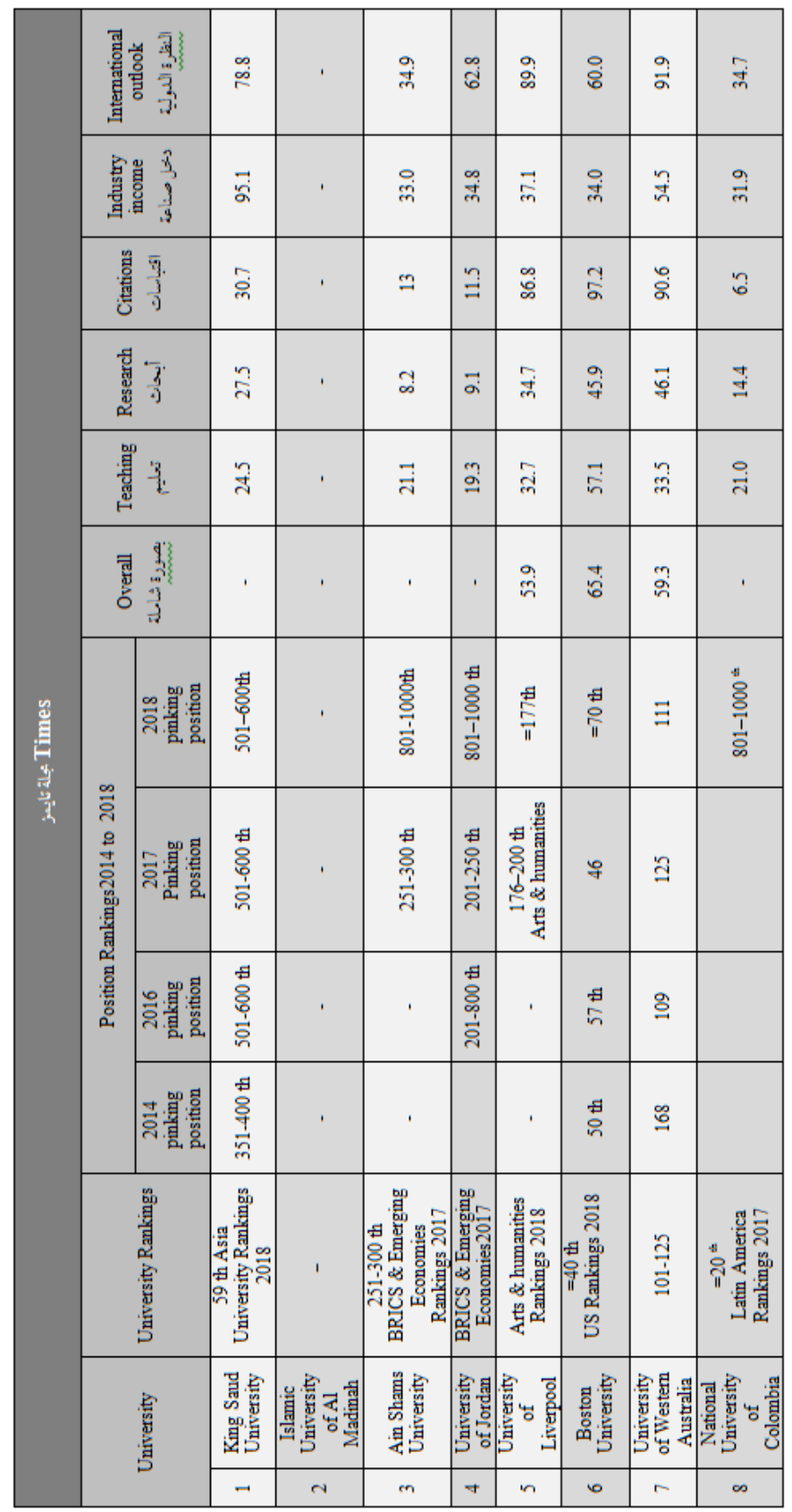

http://dx.doi.org/10.29009/ijres.2.2.5 
ويتضح من الجدول السابق اختفاء الجلمعة الإسلامية حيث السمعة الأكاديمية وفق بجلة تايمز ومقارنة بالجامعات المحلية لا يوجد تواجد وكذلك مقارنة بالجامعات الدولية لا يوجد

$$
\text { مؤشرات للسمعة الأكاديمية مقارنة بباقي الجامعات العربية والمحلية والدولية. }
$$

ومن خلال النتائج السابقة والاطار النظري للبحث والدراسات السابقة يمكن أن تعزىن

$$
\text { النتائج السابقة وتفسيرها النى ما يلي: }
$$

- الآونة الأخيرة تم استحداث عمادة البحث العلمي: هي إحدى الوحدات التابعة لوكالة

$$
\text { عمادة الشؤون العلمية، }
$$

- عدم تشجيع أعضاء هيئة التدريس وغيرهم من الباحثين علن إجراء البحوث العلمية المبتكرة، وتهيئة الوسائل والإمكانات البحثية لهم لتمكينهم من إنهاء أبحاثهم في جو علمي

$$
\text { ملائم يضمن تحقيق رؤية الجامعة ورسالتها. }
$$

- عدم دعم البحوث التي تسهم في تحقيق أهداف الجمامعة وتخدم رسالتها العلمية ورؤيتها

المستقبلية.

- قلة إعداد البحوث والدراسات العلمية الأصيلة والمبتكرة التي تسهم في إثراء المعرفة وتخدم الجلمعة والمجتمع كدراسة الظواهر والقضايا الاجتماعية الملحّة وإيجاد الحلول العلمية و العملية المناسبة ها والعمل علئ تطويرها.

- عدم التوجه في اكتشاف الباحثين المتميزين في وقت مبكر وتشجيعهم ومساندتهم ليكونوا ركيزة أساسية للبحث العلمي في الجامعة مما يُسهم في تقدم الجحامعة والوطن في شتى مجالات المعرفة.

- قلة نشر المعلومات الأكاديمية عبر موقع عمادة البحث العلمي المذكور

.(https://iu.edu.sa/Page/index/21449) - عدم متابعة نشر الإنجازات لوحدات الجامعة التي تهتم بالبحوث والدراسات العلمية

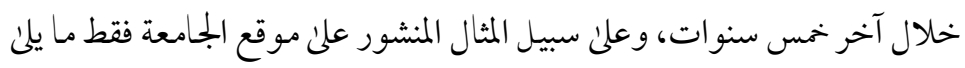




\begin{tabular}{|c|c|c|c|c|c|c|}
\hline \multicolumn{6}{|c|}{ سنوات الدعم } & \multirow[t]{2}{*}{ الكلية/ الجهة } \\
\hline الخموع & $D 1 \leqslant r V / 1 \leqslant r\}$ & $\Delta 1 \leqslant r\} / 1 \leqslant r_{0}$ & DI $\leqslant r_{0} / 1 \leqslant r \leqslant$ & $D \mid \leqslant r \leqslant / 1 \leqslant r r$ & $D 1 \leqslant r r / 1 \leqslant r r$ & \\
\hline 97 & 17 & ri & rr & rr & 10 & الشريعة \\
\hline Vr & $v$ & iv & $r$. & iv & 11 & الدعوة وأصول الدين \\
\hline$\varepsilon r$ & ir & 1. & $\Lambda$ & 0 & 7 & القرآن الكريع \\
\hline 00 & 。 & 19 & $1 \varepsilon$ & ir & . & الحديث الشريف \\
\hline$r \varepsilon$ & 9 & 1. & 7 & 0 & $\leqslant$ & اللغة العربية \\
\hline o. & $\leqslant$ & ir & 17 & 9 & 9 & معهد تعليم اللغة \\
\hline iv & 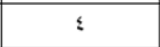 & o & 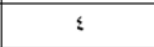 & $r$ & $r$ & العلوم - العل \\
\hline it & v & $r$ & $r$ & 1 & - & الهندسة \\
\hline$r \cdot$ & 0 & 9 & 7 & - & - & الحاسب الآلي \\
\hline$r$ & - & $r$ & - & - & - & المركز الطي \\
\hline ir & 1 & $\circ$ & $r$ & 1 & $r$ & العمادات \\
\hline$\varepsilon 1 \varepsilon$ & $\mathrm{vr}$ & $11 \varepsilon$ & 1.1 & $V \xi$ & $0 \leqslant$ & الخموع \\
\hline
\end{tabular}

\begin{tabular}{|c|c|c|c|c|c|c|}
\hline \multicolumn{6}{|c|}{ سنوات الدعم } & \multirow{2}{*}{ البرنامج } \\
\hline الجموع & $\rightarrow 1 \leq r V$ & $\rightarrow 1 \leq r 7$ & $\rightarrow 1 \leq r 0$ & $\rightarrow 1 \leq r \leq$ & $D 1 \leq r r$ & \\
\hline$r \leq r$ & $\leq 0$ & or & oᄉ & $\leq 0$ & $\leqslant r$ & تكامل \\
\hline 07 & 10 & $r \leq$ & iv & - & - & بناء \\
\hline r & 11 & 1. & - & - & - & تنمية \\
\hline $9 \leq$ & - & $r v$ & rt & rq & ir & قدرات \\
\hline$\varepsilon 1 \varepsilon$ & vi & $11 \leq$ & $1 \cdot 1$ & $v \leq$ & $0 \leq$ & الجموع \\
\hline
\end{tabular}

حيث يعد برنامج دعم أعضاء هيئة التدريس الجدد ( بناء ) : ـ هو أحد برامج دعم المشروعات البحثية في الجامعة الموجَّهة لأعضاء هيئة التدريس الجلدد، ممن هم على درجة أستاذ مساعد ولم يمضِ على تعيينهم أكثر من ثلاث سنوات، ويهدف إلى تشجيع الباحثين الجدد ومساندتهم في بداية مشوارهم البحثي مما يضمن استمرارية نشاطهم البحثي بعد مرحلة الدكتوراه، وقد بدأ تنفيذ هذا

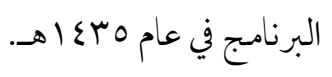
وكذلك برنامج البحوث والدراسات الوطنية ( تنمية ) : هو أحد البرامج التي تنفذها العحادة وتعنى بالبحوث والدراسات المتعلقة بالمجالات التي تخدم الجحامعة والمجتمع كدراسة الظواهر

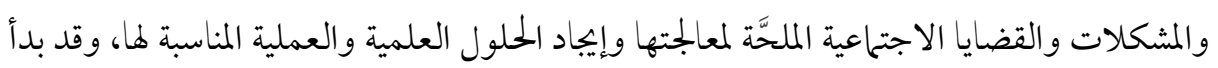
تنفيذ هذا البرنامج في عام حسع اهـ http://dx.doi.org/10.29009/ijres.2.2.5 
Dr. Elnaggar, Khaled M.

Volume (2) No. (2) 2019

(https://iu.edu.sa/Page/index/21449)

- - وكذلك جار العمل على خدمة الباحثين من خلال قاعدة المعلومات :كان عدد إفادات براءات الموضوعات للباحثين من عدد من الجامعات المحلية بواسطة قاعدة المعلومات البحثية في الجمامعة خلال آخر عامي هبع اهـ ، وجrع أهـ علن النحو التالي:

\begin{tabular}{|c|c|c|}
\hline \multicolumn{2}{|c|}{ الـ ع } & \multirow{2}{*}{ نوع البيان } \\
\hline 1436 هـ 1435 / 1435 & 1435 / 1434 هـ & \\
\hline 25 & 27 & عدد الإفادات \\
\hline
\end{tabular}

وجار إعداد ملخصات البحوث المدعومة تمهيدًا لإتاحتها إلكترونيّا: تم عمل ملخصات للبحوث المدعومة المنجزة منذ بداية برامج دعم المشروعات البحثية حتى آخر ما تم إنجازه وتسليمه من بحوث لوحدة البحوث والدراسات العلمية بالعمادة، تهيدًا لإتاحة هذه الملخصات على صفحة العحادة على الموقع الإلكتروني للجامعة، لإفادة الباحثين والتسهيل عليهم في الوصول إلى ما يحتاجون

$$
\text { توصن أبحاث. }
$$

- الاهتحام والعمل علن الوصول إلى التصنيفات العالمية الأكاديمية.

- - - تشجيع البحث العلمي في الجامعة الإسلامية علن كافة التخصصات والنشر باسم الجمامعة، في المجلات العلمية التي لها تأثير، وتشجيع الباحثين في المؤتمرات العلمية والأبحاث. - العمل علئ استقطاب الطلاب الجدد والمنظلات المهتمة بالبحث العلمي.

- - تشجيع عضو هيئة التدريس علئ حضور المؤتمرات والمشاركات العلمية ولا يكتفي بالحضور. - - إقامة ورش العمل الفعلية والتطبيقية للتعرف التصنيفات العالمية للنهوض بالجامعة. - - العمل على دعم أعضاء هيئة التدريس ومن يرغب بالنشر ومساعلتهم بالتواصل مع الهيئات والمجلات المعنية.

http://dx.doi.org/10.29009/ijres.2.2.5 
- العمل علن دعم البحث العلمي بالجامعة وكل المراكز والوحدات التابعة للجامعة بتقديم كافة الخدمات لأعضاء هيئة التدريس ومساعدتهم علن إجراء البحوث العلمية.

- - الحث بتدويل الدوريات العلمية التي تصدر عن الجامعة والعمل علن ضمن قواعد البيانات العالمية. 


\section{المراجع العربية}

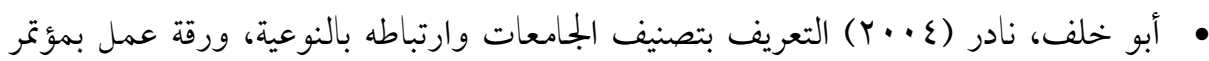
التوعية في التعليم الخاص الفلسطيني، جامعة القدس المفتوحة.

• أبو خلف، نادر (ع · †) التعريف بتصنيف الجامعات وارتباطه بالنوعية، ورقة عمل لمؤتمر النوعية في التعليم الخاص الفلسطيني، برنامج التربية وإدارة ضبط النوعية في جامعة

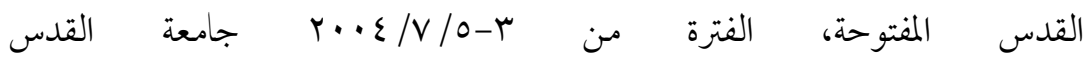
http://www.usenwes.com/u5news/edu/collge/eohome.htm.

• أحمد، سماح محمد سيد (7 • (Y) المتطلبات التربوية للارتقاء بترتيب الجامعات المصرية في التصنيفات العالمية، جامعة المنصورة، كلية التربية. -قسم أصول التربية.

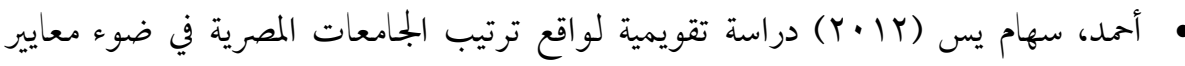
التصنيف العالمية للجامعات، مستقبل التربية العربية-مصر، مـج , 19 ع8 الأحمدي، عائشة بنت سيف ( ب r) لتصنيف العالمي لجامعات الدارسين السعوديين في الخارج :الو اقع والمأمول، بجلة العلوم التربوية والنفسية- البحرين، مج , 14ع.

• إسماعيل، طلعت حسيني (Y V · r) تعبئة موارد مالية إضافية لتلبية متطلبات التصنيفات العالمية للجامعات، دراسات تربوية ونفسية : بجلة كلية التربية بالزقازيق -مصر،عوب(90).

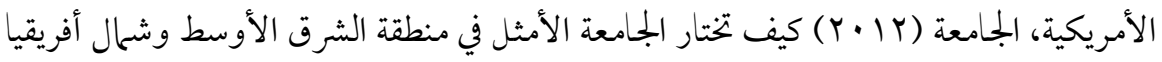
- دليل عملي للطلبة وأولياء الأمور، منشورات الجامعة الأمريكية بالشارقة. • برنامج الأمم المتحدة الإنمائي والصندوق العربي للإنهاء الاقتصادي والاجتحاعي (rا • r) تقرير التنمية الإنسانية العربية "نحو إقامة بجتمع المعرفة"، نيويورك: المكتب الإقليمي للدول العربية. 


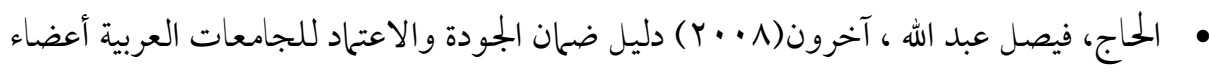

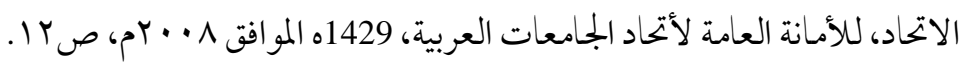
رجب، مصطفي (T + (Y) العلاقة بين العدل المعلوماتي الأكاديمي والتصنيف العلمي الأكاديمي

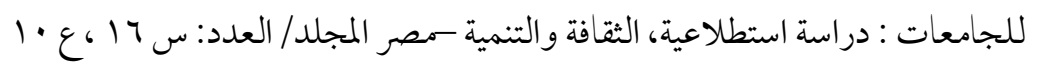

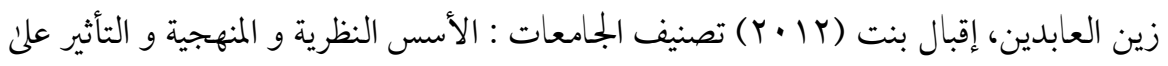

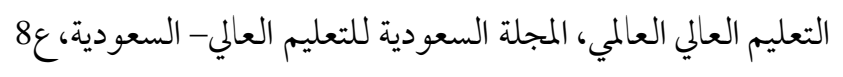

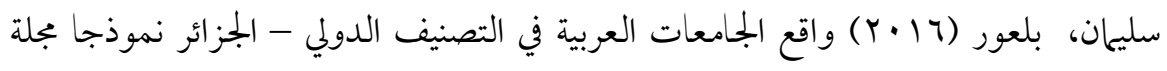

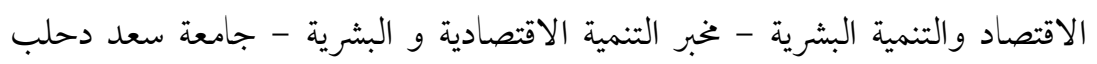

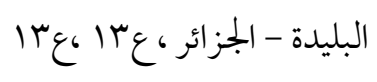

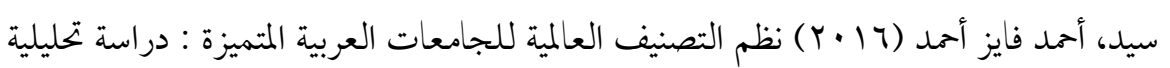

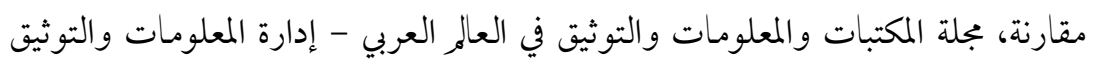

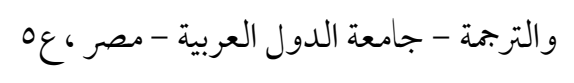

• شاكر، سوسن (ع ا • r) الجودة في المؤسسات والبرامج الجمعية، عمان، الأردن.

• صائغ، عبد الرحمن أمد (1) التصنيفات الدولية للجامعات، تجربة الجامعات السعودية،

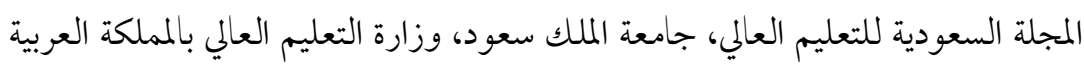

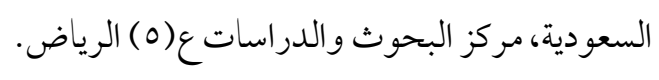

عبد الحميد، وائل شحاتة (r (Y) الجامعات العربية بين الجودة الشاملة وشهادات الجودة،

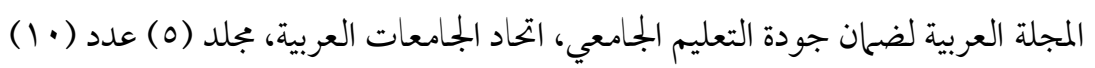




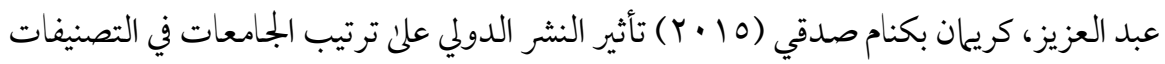

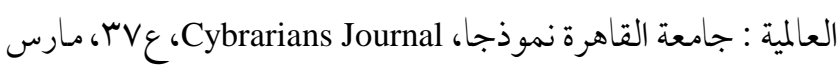

عبدالعزيز، كريان بكنام صدقي (10 ب) التصنيفات العالمية للجامعات : ناذج غختارة من

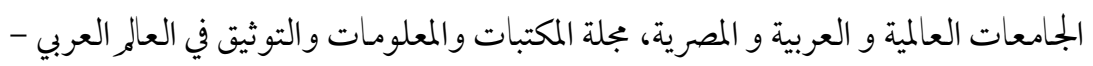

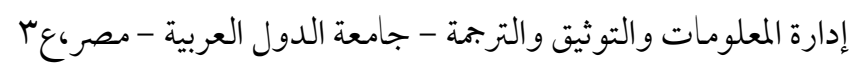

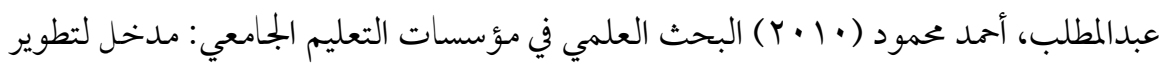

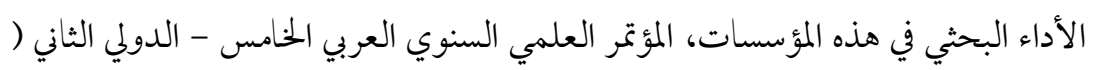

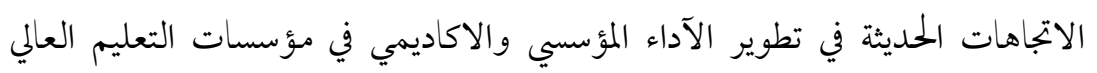

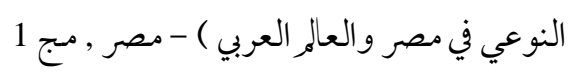

عصاصه، غازي محمد راتب وآخرون (10 · r) تأثير البوابات الإلكترونية والنشر الدولي علن

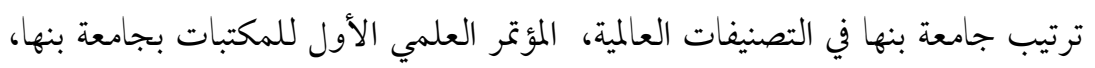

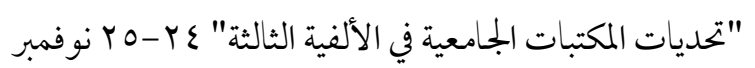

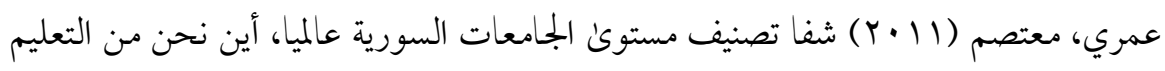
العالي؟، قضايا معلوماتية- العدد (79) - شهر تشرين الثاني

• الفيصل، بسمان (Yr\& () التصنيفات الدولية للجامعات وموقف الجمعات العربية، المجلة

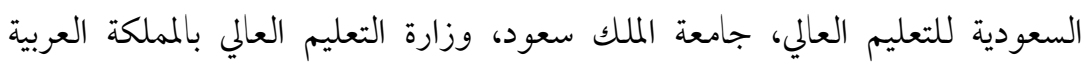

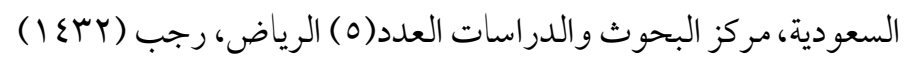

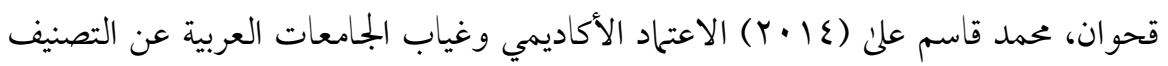

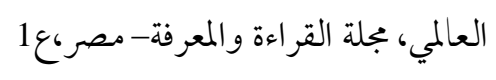

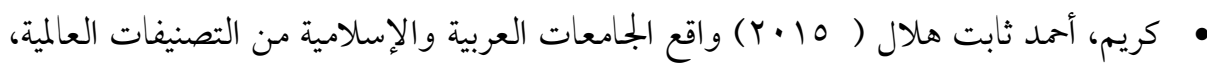

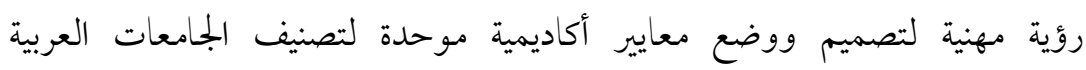

\section{http://dx.doi.org/10.29009/ijres.2.2.5}


والإسلامية، ورقة عمل المؤتمر الدولي الأول لجامعة النهضة ببنى سويف بالتعاون مع

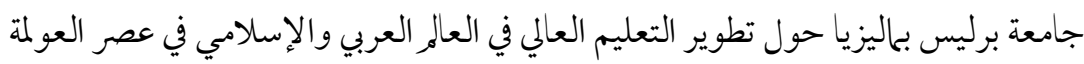

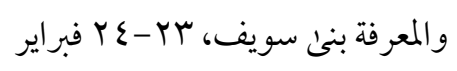

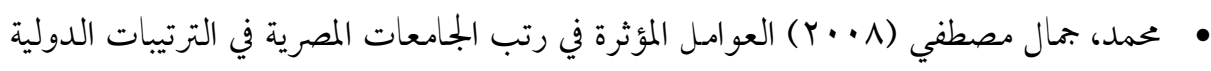
للجامعات، بجلة قطاع الدراسات التربوية، جامعة الأزهر، ع ب، ديسمبر.

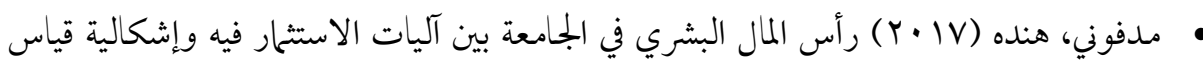

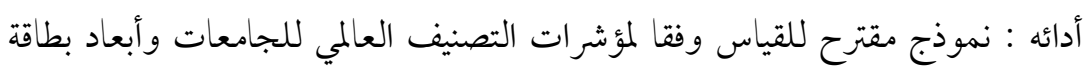

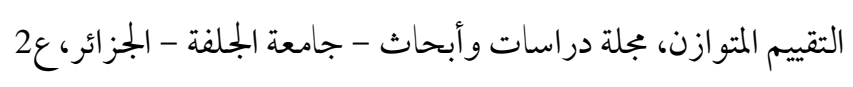

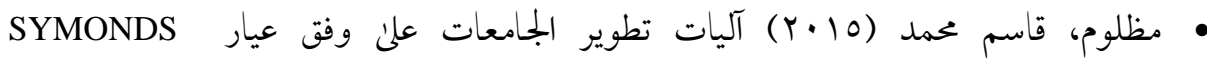
جUAEQUARELLI -QS

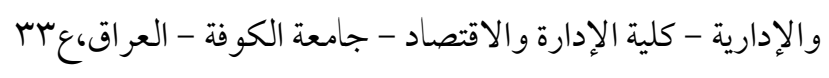

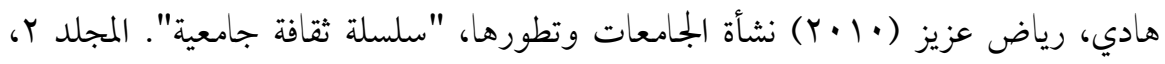

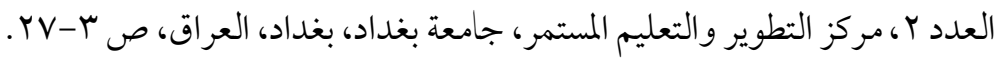

الهاشم، عادل عودة وآخرون (Y · Pr) نظام ويبومتريكس "Webometrics" لترتيب الجامعات علن الإنترنت تحليل وصفي نقدي لترتيب الجمامعات العربية، آفاق جديدة للدراسات

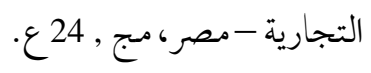

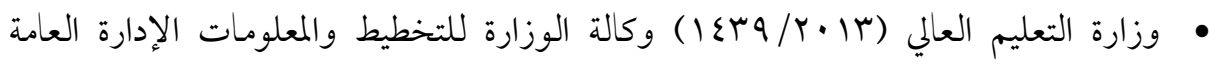

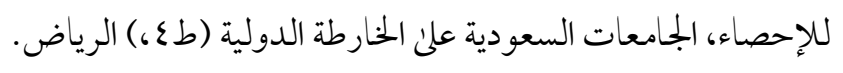

وزارة التعليم العلي بالمملكة العربية السعودية (rا •r) الجامعات السعودية علن الخحارطة الدولية، الإدارة العامة للتخطيط والإحصاء الرياضي. 
ويح، محمد عبد الرازق إبراهيم (r • ب ) التصنيفات العالمية للجامعات و موقع الجمامعات العربية

$$
\text { منها : رؤية نقدية، دراسات عربية في التربية وعلم النفس - السعودية،ع , } 41 \text { ج3 }
$$

• ياسين، سامر إبراهيم باخت وآخرون (10 ب)أهمية مؤشرات الأداء في تصنيف الجامعات على المستوئ العالمي: دراسة تحليلية لاتجاهات مدراء الجامعات السودانية الحكومية، مؤتمر قياس الأداء وتطبيق نظام المؤشرات الرئيسية في تعزيز الجمودة الشاملة في جامعات الوطن

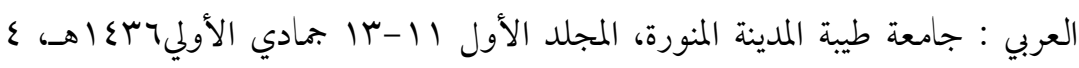

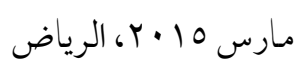




\section{References}

- Abdul Aziz, Karimman, Benkam Sidqi (2015) The Effect of International Publication on the Ranking of Universities in Global Classifications: Cairo University Model, Cybrarians Journal, p 37, March

- Abdul Hamid, Wael Shehata (2012) Arab Universities between Total Quality and Quality Certificates, Arab Journal for Quality Assurance of University Education, Union of Arab Universities, Vol. (5) (10) 219

- Abdulaziz, Karimman, Benkam Sidqi (2015) International Categories of Universities: Selected Models of International, Arab and Egyptian Universities, Library, Information and Documentation Library in the Arab World - Information Management, Documentation and Translation - Arab League - Egypt, p3

- Abu Khalaf, Nader (2004) Definition of the classification of universities and its relevance to quality, working paper of the conference on awareness in Palestinian private education, Al Quds Open University.

- Abu Khalef, Nader (2004) Definition of the classification of universities and its relevance to quality, a working paper for the Conference on Quality in Palestinian Special Education, the program of education and management of quality control at Al-Quds Open University, 3-5 / 2004/2004 Al-Quds University http: //www.usenwes .com / u5news / edu / collge / eohome.htm.

- Academic Ranking of World Universities (2018. Available at: http://www.shanghairanking.com/aboutarwu.htm 1 , Accessed on:2/3/2018

- $\quad$ Ahmadi, Aisha Bint Saif (2013) for the global classification of universities of Saudi students abroad:

- $\quad$ Ahmed, Samah Mohamed Sayed (2016) Educational requirements for upgrading the ranking of Egyptian universities in international classifications, Mansoura University, Faculty of Education. -Department of Foundations of Education.

- $\quad$ Ahmed, Siham Yassin (2012) Evaluation study of the reality of the ranking of Egyptian universities in light of the standards of the international classification of universities, the future of Arab education - Egypt, 19, p 8

- alfaysalu, bisaman (1432) International Classification of Universities and Position of Arab Universities, Saudi Journal of Higher Education, King Saud University, Ministry of Higher Education, Kingdom of Saudi Arabia, Research and Studies Center No. (5) Riyadh, 
- Al-Hashim, Adel Odeh et al. (2012) Webometrics System for the Ranking of Universities on the Internet A Critical Descriptive Analysis of the Ranking of Arab Universities, New Horizons for Business Studies - Egypt, Vol. 24, p.

- $\quad$ Baccini, A., Banfi, A., De Nicolao, G., \& Galimberti, P. (2015). University ranking methodologies. An interview with Ben Sowter about the Quacquarelli Symonds World University Ranking. RT. A Journal on Research Policy and Evaluation, 3(1).

- Bileur ,Sulaiman (2016) The reality of Arab universities in the international classification - Algeria Model Journal of Economics and Human Development Economic and Human Development Laboratory - University of Saad Dahlb Blida Algeria, p 13, p 13

- Eabdalmtlb, 'Ahmad Mahmud (2010) Scientific Research in Higher Education Institutions: An Introduction to Developing Research Performance in These Institutions, The Fifth Annual Arab Scientific Conference (Modern Trends in Developing Institutional and Academic Performance in Higher Education Institutions in Egypt and the Arab World) - Egypt, Vol. 1

- Eamari Mu'tasim (2011) The Level of the Syrian Universities' Level in the World, Where Are We from Higher Education ?, Information Issues - Issue (69) November

- $\quad$ Easasuhu, Ghazi Muhamad Ratib Wakharun (2015) The Impact of Electronic Portals and International Publications on the Ranking of Banha University in International Classifications, The First Scientific Conference of Libraries at Banha University, "Challenges of University Libraries in the Third Millennium", 24-25 November

- Grunwell, Daniel \& Sahama, Tony (2016) Delegation of access in an Information Accountability Framework for eHealth. In 9th Australasian Workshop on Health Informatics and Knowledge Management, 2-5 February 2016, Canberra, A.C.T. (In Press).

- Hadi, Riad Aziz (2010) The emergence and development of universities, "a series of university culture". Volume 2, Issue 2, Center for Development and Continuing Education, University of Baghdad, Baghdad, Iraq, pp. 3-27.

- Haj, Faisal Abdullah, Others (2008) Quality Assurance and Accreditation Guide for Arab Universities Members of the Union, General Secretariat of the Union of Arab Universities, $1429 \mathrm{H}$ corresponding to 2008 , p. 
- Ismail, Muhammad; Ranking of Universities 2 nd International Conference on Assessing Quality in Higher Education, 1 st -3rd December, 2008, Lahor Pakistan,2008,p.3.

- Ismail, Talaat Hosseini (2017) Mobilization of additional financial resources to meet the requirements of international classifications of universities, educational and psychological studies: Journal of Faculty of Education Zagazig - Egypt, p (95)

- Karim, Ahmed Thabet Helal (2015) The reality of Arab and Islamic universities of international classifications, a professional vision for the design and setting of unified academic standards for the classification of Arab and Islamic universities, the first international conference of the University of Renaissance in Beni Suef in cooperation with the University of Perlis in Malaysia on the development of higher education in the Arab and Islamic world In the age of globalization and knowledge Beni Suef, February 23-24

- $\quad$ Levin, Henry M., et al (2006) what is world a class university, prepared at the 2006 conference of the comparative $\&$ international education society, Honolulu, march 16.

- madfuni, hindah (2017) Human Capital in the University Among the investment mechanisms and the problem of measuring its performance: A proposed model for measurement according to the indicators of the international classification of universities and the dimensions of the Balanced Scorecard, Journal of Studies and Research - University of Djelfa - Algeria, p.2

- Mazloum, Qassem Mohammed (2015) The mechanisms of the development of universities in accordance with the caliber of SYMONDS QUAEQUARELLI -QS Baghdad University model of Al-Ghiri Journal of Economic and Administrative Sciences - Faculty of Management and Economics - University of Kufa - Iraq, p 33

- Ministry of Higher Education (2013/1439) Ministry of Planning and Information Agency, Department of Statistics, Saudi Universities on the International Map (I4), Riyadh.

- Ministry of Higher Education in Saudi Arabia (2013) Saudi Universities on the International Map, General Directorate of Sports Planning and Statistics.

- Mohamed Abdel Razek Ibrahim (2013) International Categories of Universities and the Arab Universities Website: Critical Vision, Arabic Studies in Education and Psychology - Saudi Arabia, p41, c3 
- $\quad$ Mohamed, Gamal Mostafa (2008) Factors Affecting the Levels of Egyptian Universities in the International Arrangements of Universities, Journal of Educational Studies Sector, Al-Azhar University, December 2,

- Qahwan, Muhammad Qasim Ali (2014) Academic Accreditation and the Absence of Arab Universities for Global Classification, Journal of Reading and Knowledge, Egypt, p.1

- QS (Quacquarelli Symonds) World University Rankings. Accessed 12ThFebruary 2018. Available at:2018. Available at:http://www.topuniversities.com/universityrankings/world-university-rankings.

- QS Stars (2018. Available at: http://www.topuniversities.com/qs- stars/qs-starsmethodology , Accessed on: 3/3/2018

- Rajab, Mustafa (2016) The Relationship between Academic Information Justice and the International Academic Classification of Universities: An Exploratory Study, Culture and Development - Egypt Volume / Issue: Q16, p10

- Ranking Web of Universities. Accessed 12ThFebruary - Available at: http://www.webometrics.info.

- $\quad$ Reality and Hope, Journal of Educational and Psychological Sciences - Bahrain, vol. 14, p

- Sayigh, eabd alrahmin 'ahmad(2011) International Classification of Universities, Experience of Saudi Universities, Saudi Journal of Higher Education, King Saud University, Ministry of Higher Education, Kingdom of Saudi Arabia, Research and Studies Center (5) Riyadh.

- Shaker, Sawsan (2014) Quality in University Institutions and Programs, Amman, Jordan.

- Shanghai Jiao Tong University (2018).Academic Ranking of World Universities. Graduate School of Education, Shanghai Jiao Tong University. Accessed 13th March 2014. Available at: http://www.shanghairanking.com/ARWU2018.html.

- $\quad$ Syed, Ahmed Fayez Ahmed (2016) Classification Systems for Arab Universities Distinguished Analytical Study, Journal of Libraries, Information and Documentation in the Arab World - Information Management, Documentation and Translation - Arab League - Egypt, p5 
- The Times Higher Education World University Rankings (2018. Available at: http://www. timeshighereducation. co .uk/world- university-rankings/Accessed on 3/3/2018

- Times World University Ranking. Accessed 12ThFebruary 2018. Available athttp://www.timeshighereducation.co.uk/world-university-rankings/2018 14/world ranking/methodology.

- UNDP and Arab Fund for Economic and Social Development (2013) Arab Human Development Report "Towards a Knowledge Society", New York: Regional Office for Arab States.

- University (2012) How to Choose the Best University in the Middle East and North Africa - A Practical Guide for Students and Parents, Publications of the American University of Sharjah.

- Usher, A\& savino, M-A Global survey of Ranking and leagne Tables, institute of Higher Education policy, College and university Ranking systems: Global perspectives and American challenges, Institute for higher Education policy, Washington Dc, 2007

- Wakefield, D. V., Manole, B. A., Jethanandani, A., May, M. E., Marcrom, S. R., Farmer, M. R, ... \& Vander Walde, N. A. (2015). Accessibility, Availability, and Quality of Online Information for United States Radiation Oncology Residencies. Practical Radiation Oncology.

- Wang,Q., Y. Cheng, and, N.C Liu,: Eds.( 2012). Building world-class universities: Different approaches to a shared goal. Rotterdam: Sense Publishers, p.2

- www.scival.com

- $\quad$ www.scopus.com

- $\quad$ Yaseen, Samer Ibrahim Bakht et al. (2015) The importance of performance indicators in the classification of universities at the global level: Analytical study of the trends of the Sudanese government university administrators, the conference measuring performance and the implementation of the system of key indicators in the promotion of total quality in the universities of the Arab world: 11-13 Jumada I, 1436 H, March 4, 2015, Riyadh

- Zine El Abidine, Iqbal Bent (2012) Classification of Universities: Theoretical, Methodological and Influential Foundations of Higher Education, Saudi Journal of Higher Education, Saudi Arabia, p8 